\title{
Modeling Dyslexic Students' Motivation for Enhanced Learning in E-learning Systems
}

\author{
RUIJIE WANG, School of Computer Science and Informatics, De Montfort University, Leicester, UK \\ LIMING CHEN, School of Computing, Ulster University, Newtownabbey, UK \\ IVAR SOLHEIM, Norsk Regnesentral/Norwegian Computing Center, Oslo, Norway
}

\begin{abstract}
E-Learning systems can support real-time monitoring of learners' learning desires and effects, thus offering opportunities for enhanced personalized learning. Recognition of the determinants of dyslexic users' motivation to use e-learning systems is important to help developers improve the design of e-learning systems and educators direct their efforts to relevant factors to enhance dyslexic students' motivation. Existing research has rarely attempted to model dyslexic users' motivation in e-learning context from a comprehensive perspective. The present work has conceived a hybrid approach, namely, combining the strengths of qualitative and quantitative analysis methods, to motivation modeling. It examines a variety of factors that affect dyslexic students' motivation to engage in e-learning systems from psychological, behavioral, and technical perspectives, and establishes their interrelationships. Specifically, the study collects data from a multi-item Likert-style questionnaire to measure relevant factors for conceptual motivation modeling. It then applies both covariance-based (CB-SEM) and variance-based structural equation modeling (PLS-SEM) approaches to determine the quantitative mapping between dyslexic students' continued use intention and motivational factors, followed by discussions about theoretical findings and design instructions according to our motivation model. Our research has led to a novel motivation model with new constructs of Learning Experience, Reading Experience, Perceived Control, and Perceived Privacy. From both the CB-SEM and PLS-SEM analyses, results on the total effects have indicated consistently that Visual Attractiveness, Reading Experience, and Feedback have the strongest effects on continued use intention.
\end{abstract}

CCS Concepts: • Human-centered computing $\rightarrow$ User models; Empirical studies in HCI; • Applied computing $\rightarrow$ E-learning; • Social and professional topics $\rightarrow$ People with disabilities;

Additional Key Words and Phrases: Motivation modeling, E-learning systems, Dyslexia

\section{ACM Reference format:}

Ruijie Wang, Liming Chen, and Ivar Solheim. 2020. Modeling Dyslexic Students' Motivation for Enhanced Learning in E-learning Systems. ACM Trans. Interact. Intell. Syst. 10, 3, Article 21 (November 2020), 34 pages. https://doi.org/10.1145/3341197

\footnotetext{
The reviewing of this article was managed by special issue associate editors Shimei Pan, Oliver Brdiczka, Andrea Kleinsmith, Yangqiu Song.

Authors' addresses: R. Wang, Poole House P259, Talbot Campus, Fern Barrow, Poole, BH12 5BB, UK; email: rwang3@bournemouth.ac.uk; L. Chen, School of Computing, Ulster University, Shore Road, Jordanstown Campus, Newtownabbey, BT37 0QB, UK; email: l.chen@ulster.ac.uk; I. Solheim, Norsk Regnesentral/Norwegian Computing Center, P.O. Box 114 Blindern, Oslo, NO-0314, Norway; email: Ivar.Solheim@nr.no.

Permission to make digital or hard copies of all or part of this work for personal or classroom use is granted without fee provided that copies are not made or distributed for profit or commercial advantage and that copies bear this notice and the full citation on the first page. Copyrights for components of this work owned by others than ACM must be honored. Abstracting with credit is permitted. To copy otherwise, or republish, to post on servers or to redistribute to lists, requires prior specific permission and/or a fee. Request permissions from permissions@acm.org. (c) 2020 Association for Computing Machinery.

2160-6455/2020/11-ART21 \$15.00

https://doi.org/10.1145/3341197
} 


\section{INTRODUCTION}

Dyslexia is a common learning difficulty pertaining to reading, writing, and spelling, causing young people not to engage fully with learning or to drop out. Although prevalent estimates vary from region to region, it has been indicated that dyslexia accounts for $4 \%-8 \%$ of the UK population $[1,2]$, and evidence shows that students' high level of learning motivation is positively associated with their good performance [3-5]. This is of course true for all students, but for those with dyslexia, it is a more acute issue. Already struggling with literacy difficulties and relatively lower academic self-worth compared with students without dyslexia, they are more likely to get demotivated and disengaged with learning, which reveals the necessity of applying motivational strategies for dyslexic students to improve their learning motivation. Looking at motivation and learning more broadly, motivation, involving both cognition and emotion, is "a natural part of any learning process" that "explains the direction and magnitude of behavior" [1]. Compared with traditional classroom learning, e-learning systems offer students a more personalized approach to learning, as users can learn anytime and anywhere with access to a computer or smartphone in a self-paced manner. In e-learning systems, highly motivated users are more likely to achieve a high level of engagement and better understanding [6]. However, the area of assistive e-learning for students with dyslexia has not obtained a comparable level of attention [3], and very little research has examined the motivational issues for dyslexic students, which only covered a specific aspect that may improve motivation such as gamification, e.g., Reference [1].

With the increasing use of mobile or web-based e-learning systems, it becomes possible to observe users' learning behavior and record data during the interaction process between users and systems to detect users' motivational states in real time. Once users' motivational states are detected, e-learning systems can respond to them dynamically by using motivational strategies or personalized actions to sustain or improve users' motivation to enhance learning efficiency, effectiveness, and enjoyment. Any intelligent tutoring system, also known as personalized learning systems, are in nature e-learning systems that provide automated adaptive guidance or services to suit an individual user's cognitive or emotional states for enhanced learning. For motivational states to be identified and corresponding strategies to be applied eventually during users' interaction with e-learning systems, establishing an explanatory framework is necessary for the users' continued intention to use e-learning systems with interdisciplinary research and theories. This area, known as user modeling, has been widely used for the personalization of various context-aware applications, including adaptive user interfaces, user recommendation systems, and personalized learning systems. Therefore, the first step of providing personalized motivating stimuli in e-learning systems is to model the factors that reflect different aspects of users' motivation to learn in e-learning systems. However, there is little work on motivation modeling in e-learning context. To the best of our knowledge, no research exists attempting to model the factors that influence dyslexic students' motivation to engage in e-learning systems. Specifically, research combining the perspectives of technology acceptance, motivation theories, and dyslexics characteristics is extremely limited. To address this knowledge gap, we develop a motivation model that can be used in the future by elearning systems to monitor and analyze a learner's motivational states and offer motivation-aware personalized learning stimuli. The present research starts with the initial motivation model developed using a qualitative approach, which then combines with a quantitative study with dyslexic students to empirically calculate the influence and weights of the motivational factors. We employ Structural Equation Modeling (SEM) as the approach of data analysis to validate the constructs and modify the relationships between them in the motivation model based on the results of the study along with the reference to prior research and theories. SEM is superior to tradition regression analysis, for it analyses measurement model and structural model together as an integral part 
of the model [7] and models relationships among multiple independent and dependent variables systematically [8]. SEM can be either a Covariance-Based (CB-SEM) or a variance-based approach, known as Partial Least Squares (PLS-SEM). CB-SEM has the assumption of multivariate normal distribution aiming at reproducing theoretical covariance matrix, while PLS-SEM, aiming at maximizing the explained variance of the dependent constructs, is advantageous in the case of small sample size as well as when the dataset does not meet the assumption of CB-SEM $[8,9]$.

Our main contributions are fourfold: first, we develop a hybrid approach to motivation modeling that marries the advantages of both qualitative and quantitative approaches. Second, we exploit a priori knowledge and dyslexic students' opinions in real-world scenario to elicit the most relevant and crucial factors when developing the motivation model in the qualitative stage. Third, we conduct SEM using both CB-SEM and PLS-SEM in the quantitative stage to fine-tune the motivation model that enables deep understanding of the model constructs and their interrelationships, with the comparison between the results from CB-SEM and PLS-SEM to ensure the methodological robustness. Finally, we create (or identify) motivational strategies as instructions according to our motivation model as examples to address both intrinsic motivation and extrinsic motivation of dyslexic students to engage in e-learning systems, as existing research on the design of e-learning systems for dyslexic students only focuses on the aspect of knowledge acquisition such as appropriate learning materials or on the style of interface design such as font type and spacing. The remaining of the article is organized as follows: Section 2 provides the related work in terms of prior motivation theories and technology acceptance perspectives as well as relevant factors in both aspects of dyslexic learners and e-learning systems. Sections 3 and 4 describe the process and methods of qualitative and quantitative motivation modeling, respectively, followed by discussion in Section 5 and conclusion in Section 6.

\section{RELATED WORK}

\subsection{Motivation Theories}

A variety of motivation theories and models have addressed the motivational factors from different perspectives to explain people's behavior intention. Theory of Planned Behavior assumes that intention immediately determines behavior, which is shaped by attitudes toward the behavior, subjective norms, and perceived behavior control [10]. Ryan and Deci [11] has distinguished extrinsic motivation as "doing something because it leads to a separable outcome" from intrinsic motivation as "doing an activity for the inherent satisfaction of the activity itself." In other words, extrinsically motivated behavior is driven by the reward of the activity, while intrinsically motivated people are attracted by the activity that they find pleasant or challenging. Researchers have also looked into factors contributing to intrinsic motivation, which are perceived challenge, feedback, perceived choice, perceived interest, curiosity, and perceived competence consisting of self-efficacy, anxiety, or emotion [12, 13]. Deci and Ryan's self-determination theory supposes that people's motivation is self-determined by the degree to which their innate psychological needs are satisfied, i.e., autonomy, competence, and relatedness [14]. Bandura's social cognitive learning theory explains behavioral intention with one's perception of control over outcome, external barriers, and selfefficacy $[15,16]$. Keller has proposed ARCS model of motivation identifying its four components being attention, relatedness, confidence, and satisfaction [17].

In contrast, there are many less theories or models targeting at behavior motivation of people with dyslexia. Daki and Savage's study has suggested that a short-term intervention improves dyslexic students' beliefs about their reading skills and perceived social support for reading, whereas the intrinsic/extrinsic motivation is more stable without improvement [18]. Glazzard has found that early diagnosis and positive interaction with peers and teachers can contribute to the 
positive self-esteem of students with dyslexia [19]. Burden and Burdett have reported that the successful learning of pupils with dyslexia is associated with low levels of depression and learning helplessness and high levels of positive self-efficacy, locus of control, and commitment to effort [20]. Only a few factors such as self-efficacy have been considered by prior research regarding the motivation of students with dyslexia with a lack of incorporation of multiple dimensions.

\subsection{Motivational Modeling in E-learning Systems and Technology Acceptance Model}

Compared to traditional classroom learning, students learning in e-learning systems usually feel less restrictions from tutors or peers, and students can take greater control for their learning experiences and outcome, which meanwhile makes it necessary and imperative to design and apply strategies in e-learning systems addressing users' motivational needs [21]. Hundreds of motivational strategies have been defined to be adopted by teachers in the language classroom to maintain and increase motivation [22]. However, most e-learning systems have only aimed at improving users' knowledge and skills. Recently, there has been increasingly more attention drawn to applying motivational strategies in e-learning systems. Several studies have proposed e-learning systems with personalized emotional or cognitive strategies to reduce users' negative states. For example, Barolli et al. have proposed an interactive web-based e-learning system trying to stimulate learning motivation by incorporating several system functions such as display of learning history, ranking, encouragement, and self-determination of learning materials [23]. Alias has designed a Malaysian e-learning environment to scaffold motivation by applying the strategies such as confidence elicitation and effort encouragement [24]. Arroyo et al.'s study has shown the noninvasive interventions using meta-cognitive strategies to promote self-reflection can re-engage users and enhance learning in a tutoring system [25]. However, those strategies to improve users' motivation lack the support of motivation models or theories.

There have also been a few attempts to design or tailor strategies in e-learning systems based on motivation models or related theories. Hurley [26] has designed an online learning environment with interventions to support users' self-efficacy and motivation, where the intervention rules were from experts constructed on the basis of Bandura's social cognitive theory and users' learning behavior. More adaptive motivational strategies were designed according to Keller's ARCS model. For example, Chang et al. [27] have embedded motivational strategies in a Mobile InquiryBased Language learning setting (M-IBL) corresponding to elements of ARCS model, showing the experiment group with the motivational strategies have a higher level of learning motivation. Derbali and Frasson [21] have attempted to assess the effect of motivational strategies embedded in a serious gameplay such as alarm trigger, informative feedback, displaying score to address the factors in ARCS model, and also their study proposed a prediction model using self-reported data and physiological sensor data, which demonstrated the possibility to use dynamic measurements to assess learners' motivation, and we can also see the possibility to automate personalized output to motivate learners according to their motivational states in real time with a prerequisite of a motivation model to be used to assess learners' real-time motivational states. However, the theory and model that their studies have used to apply motivational strategies were not constructed in e-learning context, thus failing to include crucial factors.

ICT tools including e-learning systems play an important role in supporting dyslexic students, including spell checkers, text-to-speech functionality, and speech recognition programs, mostly aiming at improving dyslexic users' literacy or knowledge skills. ICT tools applied to dyslexics are listed from a recent literature review [28] including those for reading evaluation and comprehension of texts, software, and e-readers used to promote better reading performance in dyslexics. Mobile apps, desktop apps, and web apps or extensions can serve as assistive technology to support students with dyslexia and enable them to "learn and function independently" [29]. Lindeblad 
et al.'s study [30] has found that using assistive technology as applications in smartphones and tablets could help reading-impaired children develop at the same rate as non-impaired ones and increase their school motivation. A growing part of research has attempted to predict continued intention of using e-learning systems, and motivational factors should be regarded as key determinants of the information system acceptance and usage [31]. From this perspective, Technology Acceptance Model (TAM) is the most widely adopted model to explain users' acceptance of technology by two drivers, perceived ease of use, and perceived usefulness [32]. However, this model has been criticized for its overemphasis on extrinsic motivation, so there have been many attempts to extend the model with intrinsic motivation or other factors [33]. For example, the Unified Theory of Acceptance and Use of Technology (UTAUT) model extended TAM and defined four determinants of technology use intention being performance expectancy, effort expectancy, social influence, and facilitating conditions [34]; however, contradictive results have been shown in recent research where the effect of effort expectancy on the adoption of e-learning systems became insignificant [35]. Increasing interest has been shown in recent research based on TAM. Singh et al. [36] developed a conceptual model and found that ease of use, usefulness, perceived risk, and attitude had significant effect on users' intention and recommendation to use a mobile wallet service. Park et al. [37] recently extended TAM with perceived playfulness and perceived risk for the adoption of digital devices for children education in Korean cases where buyers and users are different entities. Tawafak et al. [38] have integrated academic performance, student satisfaction, support assessment, and effectiveness with TAM to explain the continuance of intention to use the universities' learning management systems. Herrador-Alcaide et al.'s study [39] targeted at students of financial accounting and revealed that students' perception of both e-learning environment and their own skill have effect on their overall feelings of satisfaction. Hanif et al. [40] also extended TAM where subjective norm, perception of external control, system accessibility, enjoyment, and result demonstrability have a positive influence on undergraduate students' use of e-learning systems. Kimathi and Zhang [41] conducted a study in Tanzania and concluded that subjective norm, experience, enjoyment, and computer anxiety are the factors positively influencing perceived usefulness or perceived ease of use that further determine the usage intention of e-learning, while computer anxiety was found to negatively affect students' behavioral intention to use e-learning in Chang et al.'s research in Azerbaijan [42]. More recently, Mehta et al. [43] and He and Li [44] also extended TAM with human values or cultural differences; the former found the value of achievement being an important predictor of e-learning adoption, and the latter emphasized the need for digital competence training and satisfactory user interface design. It can be seen that researchers focused on different aspects of technology acceptance to make conclusions, and the effects of the factors on adoption of technology are also different in various contexts. Extending TAM with factors from other theories is still an open door for IS scholars, as pointed out by Al-Emran et al. [45].

As discussed before, motivation is a substantial issue especially for dyslexic students, but there have been very few attempts of applying motivational strategies in e-learning systems for students with dyslexia. One of the very few papers addressing this for students with dyslexia is an adaptive e-learning framework proposed by Alsobhi et al. [46] involving different dimensions of e-learning support based on TAM and dyslexia types but without consideration of motivation theories. The most motivation-related approach applied to e-learning systems for dyslexia is gamification. For example, Gooch et al. have examined the use of gamification to motivate children with dyslexia, showing that gamification can enhance dyslexic children's learning motivation [1]. However, their study fails to address more aspects of motivation for dyslexic students in a big picture; additionally, educational games may be boring for the adults with dyslexia, though they may work well on dyslexic children [47, 48], and also e-learning systems are more widely available than educational games. Therefore, we believe that research on e-learning systems based on users' motivation model 
to provide personalized motivational support has a wider range of users, which is in fact applicable to all generic users certainly including dyslexic users.

In summary, we have discussed theories and models that may offer an insight into users' motivation to engage in e-learning systems, and we have also touched the main strategies applied to e-learning systems based on motivation models or theories. However, research grounded in motivation theories for people with dyslexia has been scarce to date; what is worse, no research exists attempting to model different factors of dyslexic students' motivation in the e-learning context to our best knowledge, and only a few motivation-related factors have been considered such as gamification and self-efficacy; the design of motivational support for students with dyslexia also lacks the fundamental basis or guidance from empirically tested motivation model in e-learning context.

Our article will bring together the aspects of motivation theories and technology acceptance along with real dyslexic users' views as the ground for motivation modeling in e-learning context. The main aim of the present research is to develop a motivation model for students with dyslexia, combining the empirically tested factors from the different perspectives together to determine their continued intention to use e-learning systems, which can be used in the future as a basis and guidance for personalization rules to be implemented in e-learning systems to provide motivational support for dyslexic users' learning enhancement.

\section{QUALITATIVE MOTIVATION MODELING}

\subsection{Extended Generic Motivation Model}

Given the lack of the motivation modeling in e-learning context that combines different perspectives and the gap of modeling particularly for dyslexic users, the motivation model in our study draws insights from technology acceptance, motivation theories, and dyslexics characteristics to fill this gap. The qualitative modeling approach is first constructing the motivation model by integrating the most important and relevant factors from existing research and theories, and then conducting an empirical study with dyslexic participants followed by qualitative analysis to elicit more factors in real-world scenario, and finally incorporating the emerging factors from our empirical study into the model by referring to and inferring from existing literature. In this section, the theories and research inspiring our initial motivation modeling are listed.

From the perspective of technology acceptance, we first adopt Chang et al.'s extended TAM and Larsen et al.'s extended post-acceptance model. Chang et al. has extended TAM by introducing perceived convenience and playfulness into TAM that influence continued use intention for a mobile learning system [33]. Larsen et al.'s extended post-acceptance model [49] explains users' continued intention to use an information system (IS) with users' overall satisfaction that is influenced by their perception of usefulness and confirmation of initial expectation, stating that utilization level is positively associated with IS continuance intention and perceived task-technology fit, with the latter positively associated with perceived usefulness. They were included in our model, because one of the dyslexic users' main goals of engaging in e-learning systems is to satisfy their learning needs, so they need to perceive the system to fit their learning needs and preference, and also perceived enjoyment and perceived convenience of using the system can compensate for the learning difficulties that may be more easily experienced by dyslexic users than those without dyslexia during their learning process. Many other factors still need to be investigated to verify the effectiveness of their role to extend TAM [45], and factors that determine technology acceptance are likely to change with the target users and context $[50,51]$. Therefore, though the above-mentioned two models are believed to be the most relevant and appropriate to our research context and target users, we have also benefited from motivational theories to establish the model in addition to the 


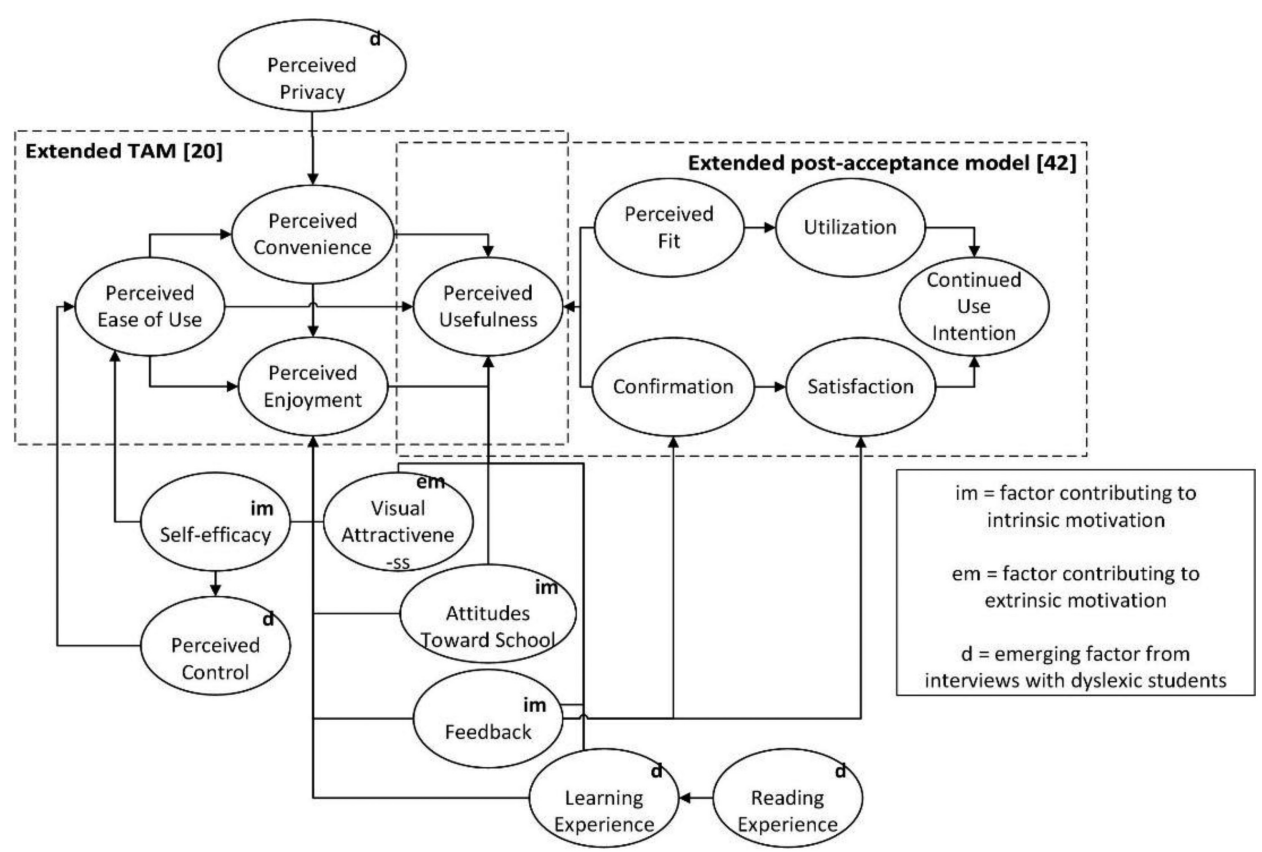

Fig. 1. The initial motivation model from the qualitative approach for dyslexic students' continued intention of using e-learning systems.

perspective of technology acceptance, and then conducted empirical studies with target users with dyslexia to further explore and confirm the model.

Drawing insights from existing research in the fields of motivation, we also extend the model that combines the two existing models mentioned above by including technology self-efficacy (also referred to as self-efficacy in the following text), visual attractiveness, attitudes toward school, and feedback as components that might affect the continued use intention for e-learning systems. Except that visual attractiveness is an extrinsic factor reflecting system features, the other three factors all reflect intrinsic motivation to compensate for the lack of intrinsic factors in the two models. The positions of the factors in the model can be seen in Figure 1. Venkatesh's study [52] has indicated that computer self-efficacy acts as a component to support users' perceived ease of use of a system. Lee et al. has also attempted to relate motivation to technology acceptance and confirmed perceived enjoyment and technology self-efficacy to be components of intrinsic motivation, and users could be intrinsically motivated through curiosity, enjoyment, or self-efficacy [53]. Furthermore, self-efficacy is associated with perceived competence, which is also a component of intrinsic motivation and can affect perceived ease of use and perceived enjoyment [12], so we made two arrows from self-efficacy to perceived ease of use and to perceived enjoyment, respectively. Visual attractiveness of the system can contribute to the perceived usefulness and entertainment value of a system [31], so we made two arrows from visual attractiveness to perceived usefulness and to perceived enjoyment, respectively. Attitudes toward school might also intrinsically regulate the learning behavior of students with dyslexia with assistive e-learning systems [3], since it has been found that attitudes toward school contribute significantly to the prediction model of information seeking behavior [54], and if a user has negative attitudes toward school, i.e., feeling that learning is boring or useless, more possibly the user will find the e-learning system less useful and less enjoyable, so we added two arrows from attitudes toward school to perceived enjoyment and 


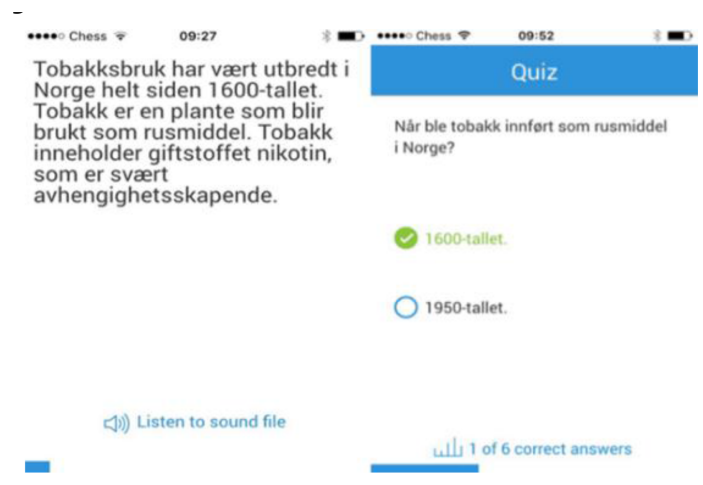

Fig. 2. An example of learning materials with text and audio (a button to read the text aloud) and feedback showing a quiz correctly answered in mYouTime.

to perceived usefulness, respectively. Additionally, feedback is also one of the components of intrinsic motivation [12], which is usually output by systems in format of text, sound, or animations during the interaction process. Feedback output by systems to users can have multiple purposes, informative or entertaining, which will help with users' involvement and interaction with the system and further result in users' perceived enjoyment and confirmation of expectation and thus the overall satisfaction of the system, so we added three arrows from feedback to perceived enjoyment, confirmation, and satisfaction, respectively.

\subsection{Towards a Dyslexia-oriented Motivation Model}

While insights were drawn from different perspectives in literature, it is worth noting that the target user group in our research is students with dyslexia, so we conducted a small-scale empirical study directly with 11 young dyslexic users aged 14-16 in Norway to elicit the motivational factors in real-world scenario. The first-hand data collected in this study will help us better understand what factors (and why) motivate or inhibit their motivation to use an e-learning system [3]. In the study, the participants were provided with a prototype of mobile learning software called mYoutime (see Figure 2) to allow them to be observed with a full picture and foster understanding of their acceptance of the learning software, and the software has built-in scientific lessons designed by experienced scientific teachers with each lesson lasting around 15 minutes.

First, the study adopted a between-subject design by separating the participants into two groups randomly. The only difference between the two groups is whether there is a button in the software for users to allow the text in the learning materials to be read aloud. Each participant was asked to do four learning tasks in the learning software. Each lesson is a learning task comprising text, audio (same content as the text, only for one of the two groups), videos, and multiple-choice questions as quizzes in between. Second, in-depth interviews were conducted individually to collect firsthand data on users' learning experience, motivations, or barriers they had in the learning process. Interview questions were designed about the general problems of the participants' daily learning experience and their specific experience about the software. Finally, all participants were asked to compare two versions of the feedback output to user by the learning software: one version is immediate feedback to indicate if an answer is correct (check mark) or not (cross mark) when a user is doing multiple-choice questions in the software; the other version is with badges and face expressions beside the check marks and cross marks to inform users about the correctness of their answers along with the function of allowing users to see the levels they have achieved. 
Data analysis consists of three stages. First, the interviews were transcribed and translated from Norwegian into English. The two groups were compared about the difference of the users' reading experience, and the opinions and experience for the two versions of feedback were compared for all users. Second, motivations and barriers of using the learning software were identified and extracted from the transcripts and then linked to corresponding motivations in literature using paper coding and thematic approaches. In case no match could be found in literature, a new theme would then be identified. The interviews were then coded and analyzed using NVivo 10 to improve the objectivity and rigor of the analysis. Nodes were created for the themes identified and references to each theme were examined. In the last stage, the emerging factors from the interview were incorporated into the motivation model.

We found that all participants preferred the version of feedback with badges and levels compared with the other version that only provides information about the correctness of their answers to the quizzes, and they had more fun with it and thought that they would be more motivated with the feedback and try harder to achieve a higher level. From the study, we found the most frequently mentioned motivational factors are learning experience (34.3\%), feedback (17.9\%), reading experience (14.9\%), and perceived usefulness (10.4\%), followed by perceived convenience $(6.0 \%)$, perceived fit $(4.5 \%)$, perceived enjoyment $(4.5 \%)$, perceived ease of use $(3.0 \%)$, perceived control $(3.0 \%)$, and perceived privacy $(1.5 \%)$. The motivational factors that have emerged from our empirical interview with dyslexic students are learning experience, reading experience, perceived control, and perceived privacy.

Integrating the perspectives of technology acceptance, motivation theories, and dyslexics characteristics, the initial motivation model developed using the qualitative approach is specified in Figure 1. In short, our qualitative motivation model is established by integrating the extended postacceptance model [49] with the extended TAM [33] and incorporating the factors inspired from prior interdisciplinary research to adapt to the characteristics of students with dyslexia to explain their motivation in e-learning context, i.e., continued use intention for e-learning systems; more importantly, the motivation model we developed also extends the prior theories and research by incorporating learning experience, reading experience, perceived control, and perceived privacy that emerged from our small-scale empirical study. The four factors emerging from the interviews with dyslexic students are discussed in more detail in the next subsection.

\subsection{Factors Emerging from the Interviews with Dyslexic Students}

Learning experience relates to the main purpose of any e-learning systems, but it has been rarely considered into the motivation model to explain users' intention of continued usage. Comments from the participants about learning experience involves the general understanding of the learning materials in terms of the difficulty levels and the experience about ways of presenting the materials that refer to text, audio, and videos in our context, and most participants preferred the videos compared with other formats of learning materials and experienced more fun when learning with videos, so we included learning experience into our model in Figure 1 and linked it to perceived usefulness and perceived enjoyment. There were still problems experienced by a couple of participants when learning with videos, indicating the videos also need to be tailored to fit individuals' learning needs in addition to the difficulty level of learning materials; for example, some participants preferred clearer and more elaborated learning contents to be presented, while others put more value on the enjoyable, pleasant experience in their learning process.

One of the main features of students with dyslexia that differentiates them from the other students is their difficulty in reading, which can explain why reading experience emerged as a separate factor from learning experience, but we still considered it to overlap with learning experience, as reflected in our model. Two features of the learning software regarding reading experience were 
examined: read aloud and text length. We found that having text read aloud or not played an important role in users' reading experience, as participants in the group without the function did not have a positive reading experience, and two of them mentioned that it would be better if the lessons could be read aloud, whereas those in the other group had a better reading experience and all of them that had seen the button did use it for the text to be read aloud. Comments about the text length were inconsistent: Some participants hoped it could be longer, while the others liked shorter paragraphs. Therefore, the text length is supposed to be personalized in the learning materials to meet different learners' needs.

Perceived control indicates users' freedom to actively manipulate the system to progress or users' sense of autonomy in the interaction process, and also control is treated as a part of ease of use in Venkatesh's model [52], so we added the relationships into our model to indicate that selfefficacy, i.e., confidence in using the system in our context, can influence perceived control, which is associated with perceived ease of use. In our empirical study, the issue of perceived control found is mostly about "undo/redo." Participants had only one chance to select an answer and could not change the answer before submitting, which led to some negative feelings about their perceived control of the interaction process.

Perceived privacy involves users' privacy concern, indicating that dyslexic students may need more private space for learning to avoid peer comparison and potential frustration, for their relatively high possibility of falling behind others, which can potentially cause frustration [55]. The participant who proposed the positive perceived privacy of using a smartphone preferred elearning using small screens over that based on large screens and usually used in classrooms, and the portability and accessibility of the device used for e-learning was also emphasized by the participant who valued privacy, so we added a relationship between perceived privacy and perceived convenience in our model.

\section{QUANTITATIVE MOTIVATION MODELING}

Starting with the qualitative motivation model, the objective of the quantitative modeling is to further investigate how the constructs function together to impact on users' motivation of continual usage of e-learning systems. The relationships between constructs in the qualitatively constructed model (Figure 1) were hypothesized or inferred based on prior research and related models, but we can hardly confirm or identify the causal relationships between the constructs in the model without quantitative data analysis, as the existing research or models have either a different target group rather than students with dyslexia or a different research context rather than e-learning systems; Therefore, it is also expected the relationships between the constructs in our model will be modified and refined with the guidance from quantitative data analysis given the shortage of theoretical references. Combining SEM with theoretical backbones, we aim to examine how the different constructs relate to each other and modify the relationships between them accordingly. SEM represents a set of statistical techniques including Confirmatory Factor Analysis (CFA) and path modeling $[56,57]$. SEM has been suggested to be treated more as CFA rather than Exploratory Factor Analysis (EFA) with multiple regression, as it is more a theory-driven confirmatory technique, but it can also be used for exploratory purposes [58]. In the present study, we used SEM not only for confirmatory purposes starting with our model in Figure 1, but also combined with exploratory purposes, because the model developed using the qualitative approach needs more evidence or re-exploration of the relationships between the constructs with the guidance of quantitative data analysis. While CB-SEM is primarily a confirmatory method, PLS-SEM is preferred to be used for exploratory research [59]. In the present study, both CB-SEM and PLS-SEM are used, and the results are compared. 
Table 1. Sample Demographics $(n=88)$

\begin{tabular}{|c|c|c|c|}
\hline Measure & Items & Frequency & Percent \\
\hline \multirow[t]{2}{*}{ Gender } & Male & 26 & $29.5 \%$ \\
\hline & Female & 62 & $70.5 \%$ \\
\hline \multirow{3}{*}{ Age } & $13-16$ & 42 & $47.7 \%$ \\
\hline & $17-19$ & 4 & $4.5 \%$ \\
\hline & $>19$ & 42 & $47.7 \%$ \\
\hline \multirow{3}{*}{ Diagnosis } & Dyslexia & 82 & $93.2 \%$ \\
\hline & Other specific language difficulties & 5 & $5.7 \%$ \\
\hline & Not tested & 1 & $1.1 \%$ \\
\hline \multirow{2}{*}{$\begin{array}{l}\text { E-learning } \\
\text { systems used }\end{array}$} & Reading and writing programs (e.g., LingDys, CD-ord) ${ }^{*}$ & 88 & $100 \%$ \\
\hline & Learning management systems (e.g., Itslearning, Blackboard) * & 79 & $89.8 \%$ \\
\hline \multirow{4}{*}{ Usage } & Every day * & 52 & $59.1 \%$ \\
\hline & In all classes * & 27 & $30.7 \%$ \\
\hline & At home doing homework * & 45 & $51.1 \%$ \\
\hline & At home in leisure time * & 25 & $28.4 \%$ \\
\hline \multirow{2}{*}{$\begin{array}{l}\text { Training and } \\
\text { Support }\end{array}$} & have been trained ${ }^{*}$ & 32 & $36.4 \%$ \\
\hline & have teacher's help * & 16 & $18.2 \%$ \\
\hline
\end{tabular}

*Items are not exclusive of each other.

\subsection{Questionnaire Design}

Our quantitative model development is started with questionnaire design to measure motivational factors and their interrelationships, followed by modification process through quantitative data analysis. All the questionnaire items used a 5-point Likert-type scale, ranging from "strongly disagree" (i.e., "1") to "strongly agree" (i.e., "5"). Our questionnaire items were mostly part of the reliable measurement instruments, collected from acknowledged literature with a few changes to reflect our specific research context (see Appendix). The emerging factors from our empirical study with students with dyslexia (i.e., learning experience, reading experience, perceived control, and perceived privacy) were operationalized by ourselves according to the definitions mentioned before and our e-learning context for dyslexic users.

The questionnaire was then translated into Norwegian and several items were removed to avoid redundancy and confusion after expert review. Finally, a pre-test was conducted to assess the wording and interpretability of the questionnaire with four Norwegian students from Dyslexia Norway. As suggested, we added optional fields for open comments under each question.

\subsection{Sampling and Data Collection}

Our sample were from the Norwegian student members of Dyslexia Norway (Dysleksi Norge), an organization founded in 1976 that works for people with reading and writing difficulties, language difficulties, and math problems. Eventually 88 young respondents filled in the online questionnaire. Table 1 displays the sample demographics.

The online survey using Google Forms was distributed through email circulated by Dyslexia Norway to the student members. They were invited to participate voluntarily in an online questionnaire (see Figure 3 for a screenshot). The respondents were asked to click on the link in the email leading to the questionnaire, and it takes 10-20 minutes to complete all the questionnaire items.

\subsection{Data Analysis}

The items used in our 5-point multi-item questionnaire are not completely from acknowledged literature; instead, they have been adapted to our specific research context, and the items measuring 


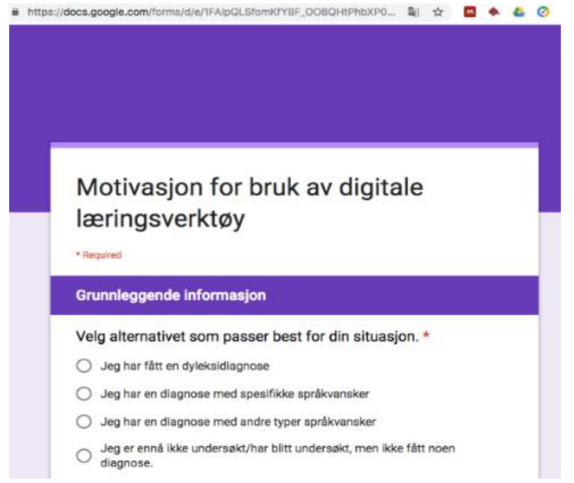

Fig. 3. A screenshot of the online questionnaire.

the emerging factors identified from our qualitative study are designed by ourselves. Therefore, the dimension reduction is necessary in the case of redundancy to reduce our data to a smaller set of more representative summary variables, so we employed EFA to assess the sampling adequacy for each construct in the model, i.e., each subscale of the questionnaire measuring one motivational factor.

Furthermore, due to the qualitative nature of the starting model in Figure 1, as mentioned before, our quantitative modeling is to collect the multi-item questionnaire data to test the significance of the impact of the constructs in the model and to further explore/confirm the relations between constructs in the model. Therefore, we performed SEM analysis to estimate the measurement model, i.e., to specify the reliability of the measured constructs in the model, and the structural model, i.e., to show the interrelationships between the constructs as a succession of structural equations. As most techniques of SEM require the assumption of multivariate normality, we tested the normality of the data of each scale that measures one factor using Shapiro-Wilk tests of normality before applying SEM. The score of each factor was calculated by averaging the scores of the questionnaire items measuring the factor. Results suggested that the data were non-normally distributed using Shapiro-Wilk test except data for the factor "utilization" $(p=0.072)$. Thus, we treated the data as non-normal distribution. Given that our dataset does not meet the normality assumption, we also used PLS-SEM, which does not require normal distribution in addition to applying a bootstrapping procedure in CB-CEM. Furthermore, in the case of our small sample size of 88 participants, PLSSEM has always larger or equal statistical power [60]. Therefore, we use both CB-SEM in AMOS 22.0 [61] and PLS-SEM in SmartPLS 3.2 [62] for our modeling and also for examining if there is any noteworthy different finding.

As stated by Goodhue et al. [63], no matter which statistical technique is used, the objectives are identical, which are (1): to ensure the reliability and validity of the measurement model; (2) to examine the statistical significance of the paths in the structural model. In CB-CEM approach, the overall model fit was reflected by the Chi-square test. A non-significant Chi-square indicates an acceptable model fit; however, as Chi-square statistic is prone to sample size [64], supplementary fit indices were suggested. Therefore, we also used CMIN/DF (Chi-square divided by degree of freedom), the Comparative Fit Index (CFI) as our supplementary incremental fit index to examine the covariance structures and the Root Mean-Square Error of Approximation (RMSEA) as a measure of absolute fit index. In contrast, the classic measures for CB-SEM are not applicable in PLS-SEM approach [65], and the most commonly used measures are R2 (explained variance), f2 (effect size), and Q2 (predictive relevance) [9]. 
Table 2. Reliability and Convergent Validity Statistics

\begin{tabular}{|c|c|c|c|c|c|c|c|c|c|c|c|c|c|c|c|}
\hline \multicolumn{2}{|c|}{$\begin{array}{c}\text { Factors } \\
\text { (i.e., constructs) }{ }^{a}\end{array}$} & PU & $\mathrm{PE}$ & CF & $\mathrm{F}$ & VA & UT & SE & AS & PC & PP & LE & $\mathrm{RE}$ & UI & $\begin{array}{l}\text { Recomm- } \\
\text { ended }\end{array}$ \\
\hline \multirow{2}{*}{$\begin{array}{l}\text { Cronbach's } \\
\text { Alpha }\end{array}$} & CB-SEM & 0.922 & 0.899 & 0.95 & 0.865 & 0.763 & 0.716 & 0.821 & $\begin{array}{l}0.367^{*} \\
0.844^{* *}\end{array}$ & $\begin{array}{l}0.468^{*} \\
0.760^{* *}\end{array}$ & $\begin{array}{c}0.549^{\star} \\
0.709^{* *}\end{array}$ & 0.7 & 0.931 & 0.818 & \multirow{2}{*}{$>0.7$} \\
\hline & PLS-SEM & 0.922 & 0.902 & 0.971 & 0.866 & 0.764 & 0.726 & 0.822 & $\begin{array}{l}0.459^{*} \\
0.846^{* *}\end{array}$ & $\begin{array}{l}0.463^{*} \\
0.765^{\text {** }}\end{array}$ & $\begin{array}{c}0.557^{*} \\
0.708^{* *}\end{array}$ & 0.728 & 0.932 & 0.819 & \\
\hline \multirow{2}{*}{$\begin{array}{l}\text { Composite } \\
\text { Reliability }\end{array}$} & CB-SEM & 0.945 & 0.933 & 0.961 & 0.909 & 0.864 & 0.835 & 0.871 & 0.907 & 0.895 & 0.837 & $\begin{array}{c}0.810^{*} \\
0.863^{* *}\end{array}$ & 0.952 & 0.893 & \multirow{2}{*}{$>0.7$} \\
\hline & PLS-SEM & 0.945 & 0.931 & 0.975 & 0.909 & 0.86 & 0.824 & 0.869 & 0.906 & 0.895 & 0.825 & $\begin{array}{l}0.814^{*} \\
0.897^{* *}\end{array}$ & 0.951 & 0.892 & \\
\hline \multirow[t]{2}{*}{ AVE } & CB-SEM & 0.813 & 0.779 & 0.803 & 0.716 & 0.681 & 0.587 & 0.532 & 0.765 & 0.81 & 0.632 & $\begin{array}{l}0.419^{*} \\
0.676^{* *}\end{array}$ & 0.831 & 0.715 & \multirow{2}{*}{$>0.5$} \\
\hline & PLS-SEM & 0.813 & 0.772 & 0.813 & 0.714 & 0.673 & 0.584 & 0.528 & 0.763 & 0.809 & 0.617 & $\begin{array}{l}0.414^{*} \\
0.686^{* *}\end{array}$ & 0.831 & 0.734 & \\
\hline \multirow{2}{*}{$\begin{array}{l}\text { minimum } \\
\text { factor } \\
\text { loading }\end{array}$} & CB-SEM & 0.803 & 0.716 & 0.84 & 0.767 & 0.789 & $\begin{array}{c}0.294^{*} \\
0.712^{* *}\end{array}$ & 0.701 & 0.836 & 0.9 & 0.752 & 0.798 & 0.877 & 0.823 & \multirow{2}{*}{$>0.5$} \\
\hline & PLS-SEM & 0.798 & 0.787 & 0.842 & 0.758 & 0.708 & $\begin{array}{c}0.197^{*} \\
0.823^{* *}\end{array}$ & 0.63 & 0.807 & 0.887 & 0.615 & 0.805 & 0.872 & 0.825 & \\
\hline
\end{tabular}

*The value before removing the item(s); ${ }^{* *}$ the value after removing the item(s).

${ }^{\mathrm{a}} \mathrm{F}=$ Feedback, LE=Learning Experience, RE =Reading Experience, Utilization =UT, SE =Technology Self-efficacy, $\mathrm{PE}=$ Perceived Ease of Use, $\mathrm{CF}=$ Confirmed Fit, $\mathrm{PP}=$ Perceived Privacy, $\mathrm{PU}=$ Perceived Usefulness, $\mathrm{PC}=$ Perceived Control, $\mathrm{VA}=$ Visual Attractiveness, AS =Attitudes Toward School and UI =Continued Use Intention.

4.3.1 Dimension reduction. EFA was run using the principle components analysis in SPSS 22.0. The data passed the thresholds for sampling adequacy (KMO MSA 0.745, Bartlett's test of sphericity 6080.583, P < 0.001). The items underlying factors "perceived enjoyment," "perceived convenience," and "satisfaction" were removed, since they demonstrated high cross-loadings in another factor "perceived ease of use." The three factors also had a very high correlation with each other ( $\mathrm{r}$ bigger than 0.8); "confirmation" and "perceived fit" were combined into one factor as "confirmed fit" representing users' confirmation of expected fit between systems and users, because the items of "confirmation" loaded high in "perceived fit" and vice versa, and there was also a high correlation between the two factors ( $\mathrm{r}$ bigger than 0.8). A possible explanation is that the enjoyment was introduced from gaming environment, which is not very applicable in the current e-learning context, and perceived convenience, confirmation, satisfaction, perceived fit, and perceived ease of use were so highly correlated with each other that they cannot be well differentiated from each other using the questionnaire items in the context of e-learning systems.

After eliminating or combining the factors mentioned above, the rest 12 factors explained $61.3 \%$ of the variance in "continued use intention." As such, preliminary evidence for convergent validity and discriminant validity was provided. The rest 12 factors (i.e., model constructs) were then used to run the CB-SEM and PLS-SEM.

4.3.2 Measurement Model. In both CB-SEM and PLS-SEM, the measurement model is assessed with indicator reliability (i.e., items' factor loadings), internal consistency reliability, convergent validity, and discriminant validity. Therefore, the results from both approaches are presented and compared in Table 2. We evaluated the internal consistency by computing the Cronbach's alpha and composite reliability. In case the alpha value of a factor is less than the recommended threshold 0.7 [66], we removed the items underlying the factor that were uncorrelated with the factor score and recalculated the score for the factor (see details of the items removed in Appendix), and all Cronbach's alpha's were bigger than 0.7 after the items were removed. The convergent validity was assessed with Average Variance Extracted (AVE) values, and we removed another two items under "learning experience" whose AVE value was less than the threshold 0.5 [67] and recalculated 
Table 3. Discriminant Validity: AVEs versus Cross-construct Squared Correlations

\begin{tabular}{|c|c|c|c|c|c|c|c|c|c|c|c|c|c|}
\hline \multicolumn{14}{|c|}{ CB-SEM } \\
\hline & $\mathrm{PU}$ & $\mathrm{PE}$ & $\mathrm{CF}$ & $\mathrm{F}$ & VA & UT & SE & AS & $\mathrm{PC}$ & $\mathrm{PP}$ & LE & $\mathrm{RE}$ & UI \\
\hline PU & 0.813 & & & & & & & & & & & & \\
\hline $\mathrm{PE}$ & 0.524 & 0.779 & & & & & & & & & & & \\
\hline $\mathrm{CF}$ & 0.531 & 0.659 & 0.803 & & & & & & & & & & \\
\hline $\mathrm{F}$ & 0.139 & 0.091 & 0.130 & 0.716 & & & & & & & & & \\
\hline$\overline{\mathrm{VA}}$ & 0.074 & 0.081 & 0.149 & 0.305 & 0.681 & & & & & & & & \\
\hline UT & 0.040 & 0.030 & 0.022 & 0.079 & 0.241 & 0.587 & & & & & & & \\
\hline $\mathrm{SE}$ & 0.058 & 0.083 & 0.104 & 0.043 & 0.092 & 0.104 & 0.532 & & & & & & \\
\hline AS & 0.078 & 0.060 & 0.053 & 0.029 & 0.035 & 0.061 & 0.050 & 0.765 & & & & & \\
\hline $\mathrm{PC}$ & 0.106 & 0.194 & 0.219 & 0.130 & 0.147 & 0.130 & 0.226 & 0.036 & 0.810 & & & & \\
\hline $\mathrm{PP}$ & 0.022 & 0.010 & 0.038 & 0.100 & 0.057 & 0.071 & 0.070 & 0.071 & 0.038 & 0.632 & & & \\
\hline $\mathrm{LE}$ & 0.026 & 0.047 & 0.070 & 0.085 & 0.110 & 0.049 & 0.071 & 0.203 & 0.095 & 0.166 & 0.676 & & \\
\hline $\mathrm{RE}$ & 0.303 & 0.288 & 0.389 & 0.143 & 0.255 & 0.151 & 0.154 & 0.052 & 0.202 & 0.104 & 0.198 & 0.831 & \\
\hline UI & 0.118 & 0.051 & 0.097 & 0.154 & 0.399 & 0.286 & 0.120 & 0.149 & 0.078 & 0.075 & 0.154 & 0.350 & 0.715 \\
\hline \multicolumn{14}{|c|}{ PLS-SEM } \\
\hline & $\mathrm{PU}$ & $\mathrm{PE}$ & $\mathrm{CF}$ & $\mathrm{F}$ & VA & UT & SE & AS & $\mathrm{PC}$ & $\mathrm{PP}$ & LE & $\mathrm{RE}$ & UI \\
\hline PU & 0.813 & & & & & & & & & & & & \\
\hline $\mathrm{PE}$ & 0.588 & 0.772 & & & & & & & & & & & \\
\hline$\overline{\mathrm{CF}}$ & 0.593 & 0.717 & 0.813 & & & & & & & & & & \\
\hline F & 0.127 & 0.093 & 0.116 & 0.714 & & & & & & & & & \\
\hline VA & 0.095 & 0.094 & 0.166 & 0.288 & 0.673 & & & & & & & & \\
\hline UT & 0.105 & 0.044 & 0.069 & 0.094 & 0.281 & 0.760 & & & & & & & \\
\hline$\overline{\mathrm{SE}}$ & 0.070 & 0.132 & 0.181 & 0.074 & 0.194 & 0.183 & 0.528 & & & & & & \\
\hline AS & 0.048 & 0.065 & 0.092 & 0.061 & 0.116 & 0.108 & 0.167 & 0.763 & & & & & \\
\hline $\mathrm{PC}$ & 0.130 & 0.182 & 0.248 & 0.135 & 0.181 & 0.176 & 0.299 & 0.103 & 0.809 & & & & \\
\hline $\mathrm{PP}$ & 0.023 & 0.016 & 0.054 & 0.068 & 0.078 & 0.136 & 0.148 & 0.135 & 0.063 & 0.617 & & & \\
\hline LE & 0.052 & 0.079 & 0.123 & 0.048 & 0.203 & 0.118 & 0.268 & 0.381 & 0.168 & 0.255 & 0.686 & & \\
\hline $\mathrm{RE}$ & 0.323 & 0.288 & 0.382 & 0.149 & 0.095 & 0.256 & 0.224 & 0.100 & 0.236 & 0.112 & 0.283 & 0.831 & \\
\hline UI & 0.136 & 0.076 & 0.104 & 0.158 & 0.445 & 0.332 & 0.190 & 0.187 & 0.101 & 0.080 & 0.264 & 0.406 & 0.734 \\
\hline
\end{tabular}

Bold scores (diagonal) are the AVEs of the individual constructs; of the diagonal are the squared correlations between the constructs; refer to Table 2 for the short names.

its score, and we also removed an item under "utilization" whose factor loading was less than 0.5 [66] (see Appendix). Afterwards, all factor loadings (the minimum one for each construct shown in Table 2), AVEs, Cronbach's alphas, and composite reliabilities exceeded the threshold values, reconfirming the validity and reliability of the measures.

Then, the individual AVEs were examined and compared with the squared correlations among the factors (see Table 3). Each factor's individual AVE surpassed the values of the squared correlations between the factor and the other factors, so discriminant validity was reconfirmed according to Fornell-Larcker criterion [67]. CB-SEM and PLS-SEM generated very similar values shown in Table 2 and Table 3, leading to the consistent results.

Finally, we tested common method bias by conducting Harman's single-factor test. First, we loaded all measurement items into one EFA principle component analysis and fixed the number of factors to be extracted as one, the result showed the factor only explained $33.521 \%$ of the variance 


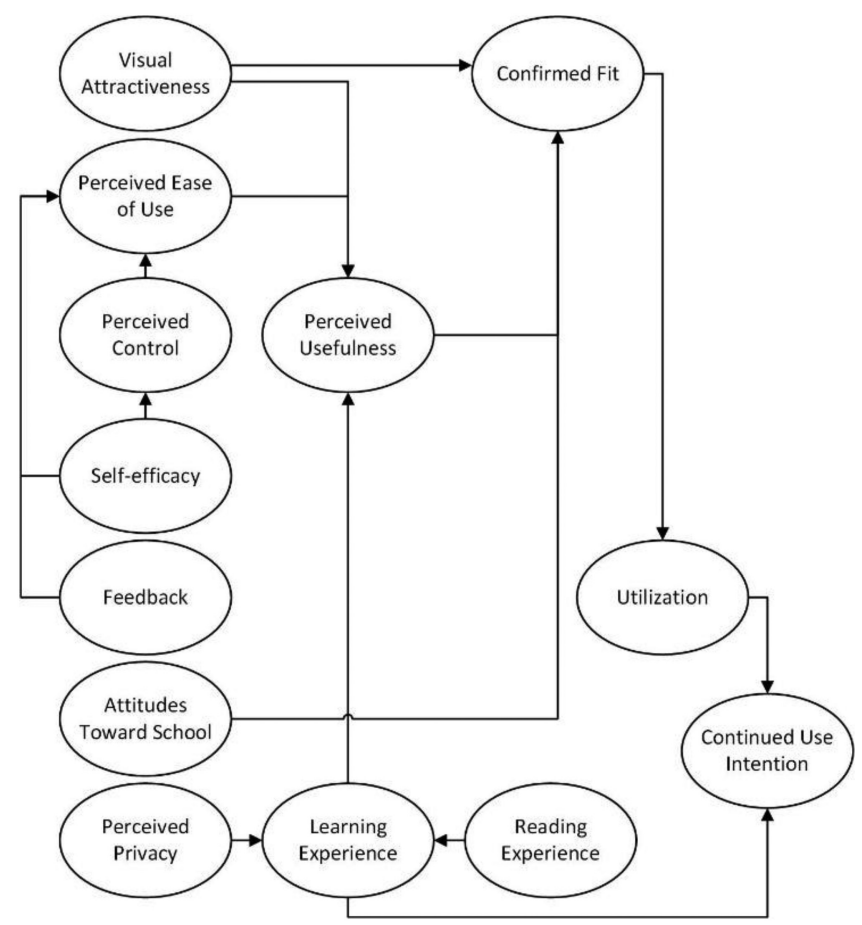

Fig. 4. New hypothesis motivation model.

rather than a majority, no indication for common method bias was found. Second, we conducted a CFA in AMOS 22.0 to assess the fit of a single factor model by loading all items on one factor; the single factor model had very poor fit $(\mathrm{CMIN} / \mathrm{DF}=45.002$; RMSEA $=0.711)$, which again indicated that common method bias was unlikely to be an issue. For PLS-SEM, a full Collinearity test is an effective approach to the identification of common method bias, which is indicated by the occurrence of VIF values greater than the 3.3 threshold [68]. The VIF values generated for all latent variables were checked in SmartPLS with the biggest VIF value being 1.541, reconfirming no contamination of common method bias.

4.3.3 Structural Model. As we had 12 factors left after the aforementioned modification, we modified the motivation model resulting from our qualitative modeling by redirecting the arrows that pointed to the factors removed previously and pointing them to the corresponding factors in which the removed items demonstrated high cross-loadings. The modified model is displayed in Figure 4. It was claimed in prior research that learning experience in ICT use should be optimized without intruding on learners' privacy [69-71], so we hypothesized that privacy perception had an impact on learning experience. Feedback was initially hypothesized to have associations with overall satisfaction and perceived enjoyment, but the two factors were removed, as they had high correlations with perceived ease of use, and it was found that emotional feedback had a significant influence on perceived ease of use when the use intention for computer-based assessment was studied [72], so we expected that feedback had an impact on perceived ease of use. Finally, the general learning experience with the e-learning system was hypothesized to impact on continued use intention in addition to perceived usefulness.

The structural model was assessed via SEM. PLS-SEM approach depends on the bootstrap procedure to evaluate the significance of the path estimates, and 1,000 bootstrap replication samples 
Table 4. Modification of Relations between Constructs in CB-SEM

\begin{tabular}{|c|c|c|}
\hline Action & Relations & According to \\
\hline Deleted & $\begin{array}{l}\text { Perceived Ease of Use } \leftarrow \text { Self-efficacy; } \\
\text { Perceived Usefulness } \leftarrow \text { Visual Attractiveness; } \\
\text { Confirmed Fit } \leftarrow \text { Attitudes Toward School; } \\
\text { Perceived Ease of use } \leftarrow \text { Feedback; } \\
\text { Continued Use intention } \leftarrow \text { Learning Experience; } \\
\text { Utilization } \leftarrow \text { Confirmed Fit; } \\
\text { Perceived Usefulness } \leftarrow \text { Learning Experience }\end{array}$ & $\begin{array}{l}\text { Bias-corrected standardized } \\
\text { regression weights (i.e., path } \\
\text { coefficients) and p values (not } \\
\text { significant at } 95 \% \text { confidence } \\
\text { level) }\end{array}$ \\
\hline Added & $\begin{array}{l}\text { Perceived Ease of Use } \rightarrow \text { Confirmed Fit; Visual Attractiveness } \\
\rightarrow \text { Utilization; } \\
\text { Attitudes Toward School } \rightarrow \text { Learning Experience; Perceived } \\
\text { Control } \rightarrow \text { Utilization; } \\
\text { Perceived Privacy } \rightarrow \text { Utilization; Reading Experience } \rightarrow \\
\text { Continued Use Intention; } \\
\text { Feedback } \rightarrow \text { Visual Attractiveness; Feedback } \rightarrow \text { Perceived } \\
\text { Control; } \\
\text { Self-efficacy } \rightarrow \text { Visual Attractiveness; Utilization } \rightarrow \text { Reading } \\
\text { Experience; } \\
\text { Confirmed Fit } \rightarrow \text { Reading Experience; Visual Attractiveness } \\
\rightarrow \text { Continued Use Intention; } \\
\text { Attitudes Toward School } \rightarrow \text { Continued Use Intention }\end{array}$ & $\begin{array}{l}\text { Modification indices; } \\
\text { Interpretability }\end{array}$ \\
\hline Added & $\begin{array}{l}\text { Self-efficacy } \leftarrow \rightarrow \text { Perceived Privacy; } \\
\text { Attitudes Toward School } \leftarrow \rightarrow \text { Perceived Privacy; } \\
\text { Self-efficacy } \leftarrow \rightarrow \text { Attitudes Toward School }\end{array}$ & $\begin{array}{l}\text { Spearman's } \\
\text { correlation test (significant at } \\
95 \% \text { confidence level); } \\
\text { Interpretability }\end{array}$ \\
\hline
\end{tabular}

were drawn with replacement from the dataset. As the data were not normally distributed, the bootstrapping techniques with 1,000 replication samples were also employed in CB-CEM, so we could correct bias and refer to the fit indices though it did not reach the standards, as suggested by prior research [56]. In CB-SEM, it was suggested that a CMIN/DF ratio of approximately 5 or less be used as an indicator of reasonable fit [73], while another researcher claimed that the ratio should be less than 3 to be acceptable [74]. CFI values close to 0.95 were suggested to be an acceptable fit between the model and the data, and RMSEA values close to 0.06 were suggested to be a good fit [75]. Therefore, it is implied that the fit of the model is poor $(\mathrm{DF}=61$, Chi-square $=326.292$, $\mathrm{p}<0.001, \mathrm{CMIN} / \mathrm{DF}=5.349, \mathrm{CFI}=0.516, \mathrm{RMSEA}=0.223$ ), suggesting modifications to the model. In PLS-SEM, R2 measures the overall effect size and variance explained in the endogenous construct for the structural model, with a value of 0.75 considered as substantial and of 0.26 considered as weak $[76,77]$. Stone-Geisser Q2 (also called Q2) greater than 0 indicates predictive relevance [78, 79]. Q2 value of 0.02 means small effect size, and 0.35 means good effect size [77]. The motivational consequence we care for (i.e., continued use intention) was explained with $44.4 \%$ of the variance by the hypothesis structural model in Figure 4 and the Q2 value is 0.287 , so both R2 and Q2 have a medium value indicating the potential for improvement. The modifications of the structural model might be different according to the results from the two approaches, so the following analyses are shown separately for CB-SEM and PLS-SEM before we compare the results of the structural model.

In CB-SEM, based on the result of bias-corrected regressions, some causal relations were not significant, so their connections were deleted, while some paths were added as suggested by the modification indices and the results of Spearman's correlation test as well as the interpretability of the causal relationships (details displayed in Table 4). In summary, perceived ease of use has an impact on confirmed fit; visual attractiveness has an effect on utilization; learning experience 


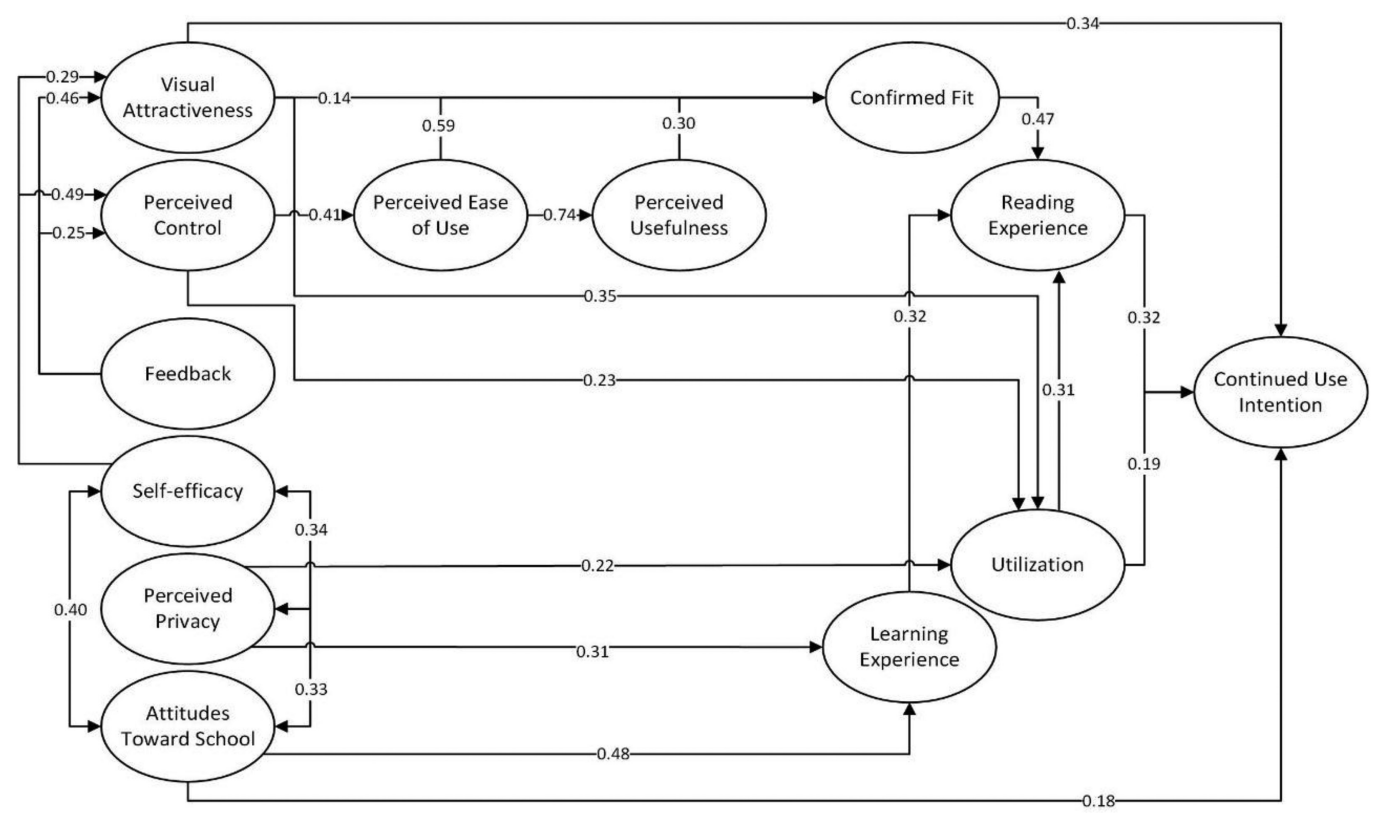

Fig. 5. CB-SEM result model of dyslexic users' motivation to engage in e-learning systems. All paths are significant (i.e., $p<0.05$, standardized $B$ is shown in the diagram).

is affected by attitudes toward school; perceived control of the system influences the utilization of system functions; perceived privacy affects the utilization of system functions, as it may generate discomfort about privacy concern of users; reading experience, attitudes toward school and visual attractiveness directly affect dyslexic users' continued use intention; feedback affects users' visual perception and perceived control during interaction process; a system tends to be perceived less attractive by users with low confidence in using the system, consistent with the case of topbottom information processing; the utilization of system functions and confirmed expectation of the system-user fit help bring about positive reading experience; also, based on Spearman's correlation test, we added correlations between three intrinsic factors, indicating self-efficacy, attitudes toward school, and perceived privacy are inter-correlated.

In addition, as mentioned before, reading experience is crucial to dyslexic students, so we separated it from learning experience. We reversed the original relation between them given the biascorrected regression estimates in AMOS. Comparing two possible causal relations, we found that learning experience has a bigger effect on reading experience (unstandardized $\beta=0.421, p<0.001$ ) compared to the other reverse way (unstandardized $\beta=0.221, p<0.001$ ); this may be because that learning need is directly related to the eventual purpose of the usage; therefore, as users' learning expectation is fulfilled, the reading is also likely to be recalled as a positive experience. An examination of the indices of fit suggested that the modified model adequately fitted the data (Chi-square=73.522; $\mathrm{DF}=54$; probability level=0.04; $\mathrm{CMIN} / \mathrm{DF}=1.362 ; \mathrm{CFI}=0.964 ; \mathrm{RMSEA}=0.064$ ); the standardized version of the final model is displayed in Figure 5.

In PLS-SEM, first the insignificant paths between constructs were removed according to the path coefficients and its significance level through the T-statistics test using the bootstrapping procedure mentioned above. The removed paths and the statistics are detailed in Table 5. Meanwhile, adding paths to or from the removed constructs is necessary to remain the constructs with the predictive relevance through direct or indirect connection to continued use intention in the model 
Table 5. Modification of Relations between Constructs in PLS-SEM

\begin{tabular}{|c|c|c|}
\hline Action & $\begin{array}{ll}\text { Relations } \\
\end{array}$ & According to \\
\hline Deleted & $\begin{array}{l}\text { Perceived Ease of Use } \leftarrow \text { Self-efficacy } \\
\text { Perceived Usefulness } \leftarrow \text { Visual Attractiveness } \\
\text { Confirmed Fit } \leftarrow \text { Attitudes Toward School } \\
\text { Perceived Ease of use } \leftarrow \text { Feedback } \\
\text { Continued Use intention } \leftarrow \text { Learning Experience } \\
\text { Utilization } \leftarrow \text { Confirmed Fit } \\
\text { Perceived Usefulness } \leftarrow \text { Learning Experience } \\
\text { Continued Use Intention } \leftarrow \text { Utilization }\end{array}$ & $\begin{array}{l}\text { Standardized path } \\
\text { coefficients and t values/p } \\
\text { values (not significant at 95\% } \\
\text { confidence level) }\end{array}$ \\
\hline Added & $\begin{array}{l}\text { Perceived Ease of Use } \rightarrow \text { Confirmed Fit; } \\
\text { Visual Attractiveness } \rightarrow \text { Utilization; } \\
\text { Attitudes Toward School } \rightarrow \text { Learning Experience; } \\
\text { Perceived Control } \rightarrow \text { Utilization } \\
\text { Perceived Privacy } \rightarrow \text { Utilization } \\
\text { Reading Experience } \rightarrow \text { Continued Use Intention } \\
\text { Feedback } \rightarrow \text { Visual Attractiveness } \\
\text { Feedback } \rightarrow \text { Perceived Control } \\
\text { Self-efficacy } \rightarrow \text { Visual Attractiveness } \\
\text { Utilization } \rightarrow \text { Reading Experience } \\
\text { Confirmed Fit } \rightarrow \text { Reading Experience } \\
\text { Visual Attractiveness } \rightarrow \text { Continued Use Intention }\end{array}$ & $\begin{array}{l}\text { Spearman's } \\
\text { correlation test (significant at } \\
95 \% \text { confidence level); } \\
\text { Interpretability }\end{array}$ \\
\hline
\end{tabular}

for further analysis instead of removing them imprudently. The paths added were also supported by Spearman's correlation test and interpretability; each time a path was added, it was tested in PLS-SEM and might be removed in case an added path was found as insignificant in terms of the path coefficients in PLS-SEM. The final modifications are detailed in Table 5.

Same as that in CB-SEM, the path from reading experience to learning experience was reversed to ensure that both constructs have a predictive relevance on continued use intention through a direct or indirect effect, since the effect of learning experience on continued use intention was found insignificant and thus removed. Compared with CB-SEM, the differences of the results are twofold: (1) two paths (i.e., Attitudes Toward School $\rightarrow$ Continued Use Intention; Utilization $\rightarrow$ Continued Use Intention) are only significant in the model resulted from CB-SEM, whereas they do not exist in the model resulting from the PLS-SEM analyses due to insignificance; (2) the arrows in PLS-SEM are always single-headed and it cannot model undirected correlations [80], so the three correlations in CB-SEM approach between the constructs, namely, attitudes toward school, self-efficacy, and perceived privacy, were not re-examined in PLS-SEM approach. What is worth mentioning is that the two paths that were significant in CB-SEM approach were not very insignificant, though they were removed from the model in PLS-SEM approach; instead, they were insignificant but close to the significance threshold at 0.05 level ( $p$ value is 0.073 and $p=0.052$ for the effect of attitudes toward school and utilization on continued use intention, respectively).

As already mentioned, the common measures in PLS-SEM to evaluate a model are different from those in CB-SEM. R2 value for continued use intention in our model is 0.543 , indicating $54.3 \%$ of the variance in continued use intention is explained by the model, which is pretty good, as values above 0.33 are considered as moderate [81]. Q2 value for continued use intention is 0.359 , indicating the predictive relevance in our model is high [77]. The standardized version of the final model from PLS-SEM is displayed in Figure 6. The path coefficients and significance levels from both approaches are listed in Table 6. In particular, f2 for each path is shown for PLS-SEM, which measures the effect size by calculating the change in $\mathrm{R} 2$ when a construct is removed from the 


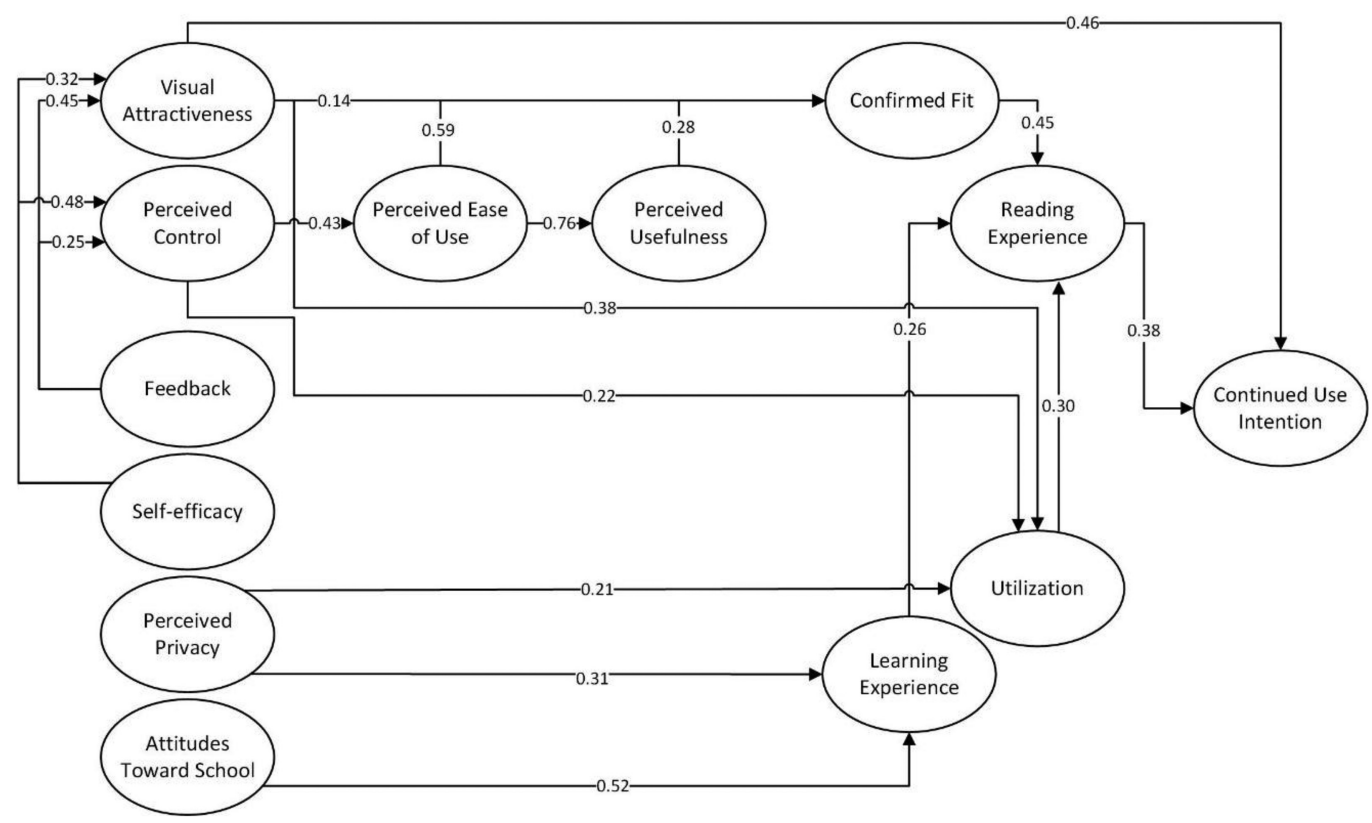

Fig. 6. PLS-SEM result model of dyslexic users' motivation to engage in e-learning systems. All paths are significant (i.e., $p<0.05$, standardized $ß$ is shown in the diagram).

model. Following Cohen [82] where 0.02, 0.15, and 0.35 represent a weak, moderate, and strong effect size, respectively, the f2 values show the effect size in our model is generally moderate or high.

4.3.4 Mediation Analysis. The path diagrams of both Figure 5 and Figure 6 from CB-SEM and PLS-SEM analyses, respectively, include the standardized estimates of the causal relations for the indirect and direct effects. Following the mediation analysis procedure [83], the direct, indirect, and total effects of the motivational factors on the consequence along with the mediation type and mediators, if applicable, are listed in Table 7. Except reading experience that only has a direct effect on continued use intention (i.e., motivational consequence), all the other constructs (i.e., motivational factors) influence the consequence through either full or partial mediation. While visual attractiveness and reading experience (and attitudes toward school and utilization from CB-SEM) have both a direct effect and an indirect effect through partial mediation on continued use intention, all the other motivational factors influence continued use intention only indirectly through full mediation. More discussions on mediators are provided in Section 5.3.

\section{DISCUSSION}

In the present study, we designed a multi-item questionnaire and used both PLS-SEM and CBSEM techniques to explore and confirm the constructs and their interrelationships in the initial motivation model that we developed using qualitative approach upon the prior theories and research together with an empirical study. Specifically, a motivation model within the context of e-learning for students with dyslexia was explored and confirmed, which integrated the intrinsic and extrinsic motivation factors and dyslexics characteristics into the extended post acceptance model proposed by Larsen et al. [49] and the extended technology acceptance model proposed by Chang et al. [33]. The motivation model developed in this article will progress the insight into the 
Table 6. CB-SEM and PLS-SEM Results Comparison

\begin{tabular}{|c|c|c|c|}
\hline \multirow[t]{2}{*}{ Relations } & \multirow{2}{*}{$\frac{\text { CB-SEM }}{\text { Path Coefficients } \beta}$} & \multicolumn{2}{|c|}{ PLS-SEM } \\
\hline & & Path Coefficients $\beta$ & Effect Size $\mathrm{f}^{2}$ \\
\hline $\begin{array}{l}\text { Attitudes Toward School } \rightarrow \text { Learning } \\
\text { Experience }\end{array}$ & $0.481^{* *}$ & $0.520^{* *}$ & 0.459 \\
\hline Confirmed Fit $\rightarrow$ Reading Experience & $0.470^{* *}$ & $0.452^{* *}$ & 0.402 \\
\hline Feedback $\rightarrow$ Perceived Control & $0.254^{*}$ & $0.246^{*}$ & 0.086 \\
\hline Feedback $\rightarrow$ Visual Attractiveness & $0.464^{* *}$ & $0.449^{* *}$ & 0.302 \\
\hline Learning Experience $\rightarrow$ Reading Experience & $0.320^{* *}$ & $0.255^{*}$ & 0.122 \\
\hline Perceived Control $\rightarrow$ Perceived Ease of Use & $0.409^{* *}$ & $0.425^{* *}$ & 0.221 \\
\hline Perceived Control $\rightarrow$ Utilization & $0.231^{*}$ & $0.217^{*}$ & 0.060 \\
\hline Perceived Ease of Use $\rightarrow$ Confirmed Fit & $0.594^{* *}$ & $0.588^{* *}$ & 0.638 \\
\hline Perceived Ease of Use $\rightarrow$ Perceived Usefulness & $0.740^{* *}$ & $0.755^{* *}$ & 1.325 \\
\hline Perceived Privacy $\rightarrow$ Learning Experience & $0.305^{* *}$ & $0.314^{* *}$ & 0.168 \\
\hline Perceived Privacy $\rightarrow$ Utilization & $0.217^{*}$ & $0.211^{*}$ & 0.064 \\
\hline Perceived Usefulness $\rightarrow$ Confirmed Fit & $0.302^{* *}$ & $0.283^{*}$ & 0.147 \\
\hline $\begin{array}{l}\text { Reading Experience } \rightarrow \text { Continued Use } \\
\text { Intention }\end{array}$ & $0.315^{* *}$ & $0.375^{* *}$ & 0.209 \\
\hline Self-efficacy $\rightarrow$ Perceived Control & $0.489^{* *}$ & $0.478^{* *}$ & 0.326 \\
\hline Self-efficacy $\rightarrow$ Visual Attractiveness & $0.294^{*}$ & $0.321^{*}$ & 0.155 \\
\hline Utilization $\rightarrow$ Reading Experience & $0.312^{* *}$ & $0.304^{* *}$ & 0.183 \\
\hline Visual Attractiveness $\rightarrow$ Confirmed Fit & $0.142^{*}$ & $0.142^{*}$ & 0.078 \\
\hline $\begin{array}{l}\text { Visual Attractiveness } \rightarrow \text { Continued Use } \\
\text { Intention }\end{array}$ & $0.344^{* *}$ & $0.457^{* *}$ & 0.310 \\
\hline Visual Attractiveness $\rightarrow$ Utilization & $0.354^{* *}$ & $0.377^{*}$ & 0.177 \\
\hline $\begin{array}{l}\text { a Attitudes Toward School } \rightarrow \text { Continued Use } \\
\text { Intention }\end{array}$ & $0.176^{*}$ & Non-existing due & insignificance \\
\hline${ }^{a}$ Utilization $\rightarrow$ Continued Use Intention & $0.190^{*}$ & Non-existing due & insignificance \\
\hline$\overline{{ }^{a} \text { Self-efficacy } \leftarrow \rightarrow \text { Attitudes Toward School }}$ & $b_{0} 0.397^{* *}$ & Not App & cable \\
\hline $\begin{array}{l}\text { a Perceived Privacy } \longleftrightarrow \rightarrow \text { Attitudes Toward } \\
\text { School }\end{array}$ & $b_{0.333^{*}}$ & Not App & cable \\
\hline${ }^{{ }^{a} \text { Self-efficacy } \leftarrow \rightarrow \text { Perceived Privacy }}$ & $b_{0.340^{*}}$ & Not App & cable \\
\hline
\end{tabular}

All path coefficients are standardized; a- paths only existing in the model resulted from CB-SEM; b- correlation estimates; *significant at 0.05 level; ** significant at 0.001 level.

motivational processes of students with dyslexia that account for varying levels of motivation to engage in e-learning systems, i.e., continued use intention for e-learning systems. The most constructs in the proposed model including all emergent factors from our empirical study with dyslexic students [3] were supported by the analysis results of quantitative study, except that several factors ("perceived enjoyment," "perceived convenience," and "satisfaction") were removed and two factors ("confirmation" and "perceived fit") were combined due to high cross-loadings, while the interrelationships were altered in the model based on the results from CB-SEM and PLS-SEM along with prior research or theories.

\subsection{Key Findings}

From our empirical study, we have identified four factors (i.e., learning experience, reading experience, perceived control, and perceived privacy) and incorporated them into the motivation model. Consistent with our qualitatively constructed model, perceived usefulness is influenced by 
Table 7. Standardized Direct, Indirect, and Total Effect on Continued Use Intention

\begin{tabular}{|c|c|c|c|c|c|c|c|c|c|c|}
\hline & \multicolumn{2}{|c|}{ Direct Effect } & \multicolumn{2}{|c|}{ Indirect Effect } & \multicolumn{2}{|c|}{ Mediators } & \multicolumn{2}{|c|}{ Mediation Type } & \multicolumn{2}{|c|}{ Total Effect } \\
\hline & CB-SEM & PLS-SEM & $\begin{array}{l}\text { CB- } \\
\text { SEM }\end{array}$ & $\begin{array}{l}\text { PLS- } \\
\text { SEM }\end{array}$ & $\begin{array}{l}\text { CB- } \\
\text { SEM } \\
\end{array}$ & $\begin{array}{l}\text { PLS- } \\
\text { SEM }\end{array}$ & $\begin{array}{l}\text { CB- } \\
\text { SEM } \\
\end{array}$ & $\begin{array}{l}\text { PLS- } \\
\text { SEM }\end{array}$ & $\begin{array}{l}\text { CB- } \\
\text { SEM } \\
\end{array}$ & $\begin{array}{l}\text { PLS- } \\
\text { SEM } \\
\end{array}$ \\
\hline $\begin{array}{l}\text { Attitudes Toward } \\
\text { School }\end{array}$ & 0.176 & $\begin{array}{c}\text { indirect } \\
\text { only }\end{array}$ & 0.048 & 0.05 & & & partial & full & 0.225 & 0.05 \\
\hline Confirmed Fit & \multicolumn{2}{|c|}{ indirect only } & 0.148 & 0.169 & \multicolumn{2}{|c|}{$\mathrm{RE}$} & \multicolumn{2}{|c|}{ full } & 0.148 & 0.169 \\
\hline Feedback & \multicolumn{2}{|c|}{ indirect only } & 0.246 & 0.255 & \multicolumn{2}{|c|}{$\begin{array}{c}\text { RE, CF, UT, PE, } \\
\text { PC, PU, VA }\end{array}$} & \multicolumn{2}{|c|}{ full } & 0.246 & 0.255 \\
\hline $\begin{array}{c}\text { Learning } \\
\text { Experience }\end{array}$ & \multicolumn{2}{|c|}{ indirect only } & 0.101 & 0.096 & \multicolumn{2}{|c|}{$\mathrm{RE}$} & \multicolumn{2}{|c|}{ full } & 0.101 & 0.096 \\
\hline Perceived Control & \multicolumn{2}{|c|}{ indirect only } & 0.116 & 0.082 & \multicolumn{2}{|c|}{$\begin{array}{l}\text { RE, CF, UT, PE, } \\
\text { PU }\end{array}$} & \multicolumn{2}{|c|}{ full } & 0.116 & 0.082 \\
\hline $\begin{array}{c}\text { Perceived Ease of } \\
\text { Use }\end{array}$ & \multicolumn{2}{|c|}{ indirect only } & 0.121 & 0.136 & \multicolumn{2}{|c|}{ RE, CF, PU } & \multicolumn{2}{|c|}{ full } & 0.121 & 0.136 \\
\hline Perceived Privacy & \multicolumn{2}{|c|}{ indirect only } & 0.093 & 0.054 & \multicolumn{2}{|c|}{ RE, LE, UT } & \multicolumn{2}{|c|}{ full } & 0.093 & 0.054 \\
\hline $\begin{array}{c}\text { Perceived } \\
\text { Usefulness } \\
\end{array}$ & \multicolumn{2}{|c|}{ indirect only } & 0.045 & 0.048 & \multicolumn{2}{|c|}{$\mathrm{RE}, \mathrm{CF}$} & \multicolumn{2}{|c|}{ full } & 0.045 & 0.048 \\
\hline Reading Experience & 0.315 & 0.375 & \multicolumn{2}{|c|}{ direct only } & \multicolumn{2}{|c|}{ no mediation } & \multicolumn{2}{|c|}{ no mediation } & 0.315 & 0.375 \\
\hline Self-efficacy & \multicolumn{2}{|c|}{ indirect only } & 0.194 & 0.208 & \multicolumn{2}{|c|}{$\begin{array}{c}\text { RE, CF, UT, PE, } \\
\text { PC, PU, VA }\end{array}$} & \multicolumn{2}{|c|}{ full } & 0.194 & 0.208 \\
\hline Utilization & 0.19 & $\begin{array}{c}\text { indirect } \\
\text { only }\end{array}$ & 0.098 & 0.114 & \multicolumn{2}{|c|}{$\mathrm{RE}$} & partial & full & 0.288 & 0.114 \\
\hline $\begin{array}{c}\text { Visual } \\
\text { Attractiveness }\end{array}$ & 0.344 & 0.456 & 0.123 & 0.067 & \multicolumn{2}{|c|}{$\mathrm{RE}, \mathrm{CF}$} & \multicolumn{2}{|c|}{ partial } & 0.467 & 0.523 \\
\hline
\end{tabular}

All effects are significant at 0.05 level; refer to Table 2 for the short names.

perceived ease of use; perceived ease of use is influenced by perceived control; perceived control is affected by self-efficacy. Our research has also yielded new findings: The study reveals direct effects of visual attractiveness and reading experience on continued use intention from both CBSEM and PLS-SEM analyses consistently, while CB-SEM also results in the significant direct effects of attitudes toward school and utilization on continued use intention, which is the only difference between the two structural models in terms of causal relations from the two approaches. Both approaches have implied the importance of visual attractiveness, reading experience, and feedback with respect to their total effects on continued use intention. It is found that feedback has an influence on both perceived control and visual attractiveness. Positive and informative feedback appearing usually in visual form works as a kind of positive reinforcement for users, which improves users' sense of control during interaction process and the perceived visual appeal of the system. Visual attractiveness and reading experience are found to be the strongest predictors of continued use intention, probably because our respondents are young students with dyslexia, and they are more likely to be sensitive to visually attractive interface and put more value on reading experience than those without dyslexia. The influence of visual attractiveness is also mediated by utilization. Utilization explains the acceptance of the functions of e-learning systems instead of systems per se, and visual attractiveness is related to the curiosity, which can trigger the interest and engagement in technology according to prior research [49]. That may explain the effect of visual attractiveness on utilization. In other words, if an e-learning system is more visually attractive, more possibly the user will fully utilize the system functions; therefore, the user will be more likely to have continued use intention.

The influences of learning experience and confirmed fit on continued use intention were found to be fully mediated by reading experience, meaning the two factors will hardly exert their impact 
on use intention if a user's need for good reading experience is not fulfilled. The influences of perceived control and perceived privacy were fully mediated by utilization; that is, a user's improved sense of control and perceived protection for privacy issue will positively impact the utilization of the system functions, thereby improving the user's intention of continued use. Confirmed fit is influenced by the system-related extrinsic factors, perceived usefulness, perceived ease of use, and visual attractiveness; that is, if a user perceives the e-learning system to be useful, easy to use, and visually attractive, more possibly the user will confirm the fit of the system to his or her own needs. Compared with recent research that found a positive effect of relatedness on perceived ease of use, in which relatedness was from the self-determination theory, meaning that it was completely in intrinsic level [84], confirmed fit in our present study is similar with relatedness but goes further by incorporating users' confirmed expectation after the usage, so the order of occurrence is different from that of relatedness, and confirmed fit involves both intrinsic-level and extrinsic-level motivation.

Users' self-efficacy also has an impact on the visual attractiveness of the system, and learning experience is influenced by attitudes toward school and perceived privacy, which emphasizes the importance of intrinsic motivation. Attitudes toward school intrinsically regulates learning behavior and has been found to be a predictor of information seeking behavior [22], thus, if someone has a negative attitude toward school, he or she will tend to have a negative intention of learning behavior, which may explain why the general learning experience is also affected in this case.

\subsection{Theoretical Findings}

We found that the constructs in the final motivation model integrating multidisciplinary perspectives can be grouped into different tiers: intrinsic factors (i.e., self-efficacy; feedback; attitudes toward school; perceived privacy), extrinsic factors (i.e., perceived usefulness; perceived ease of use; perceived control; visual attractiveness), and motivation mediators (i.e., confirmed fit; learning experience; reading experience; utilization), which all work on the consequence tier (i.e., continued use intention). This does not mean the factors in the three tiers function in a complete sequenced order; instead, their associations are heavily intertwined. Overall, it reveals an apparent path that intrinsic factors and extrinsic factors influence together the consequence directly or indirectly through the motivation mediators in the final motivation model. Detailed grouping and sequence of the model constructs is shown in Figure 7.

Prior research that linked user motivations to behavioral intentions has either relied on general technology perceptions (e.g., Reference [85]) or socio-psychological perceptions (e.g., Reference [86]) as motivators behind the behavior, but the modeling of motivational factors reflecting extrinsic motivation, intrinsic motivation, and potentially important system/user-specific features were rarely taken into account [31]. In contrast, the present study has progressed insights into the motivations of users with dyslexia behind the engagement in e-learning systems by proposing a motivation model combining extrinsic motivation, intrinsic motivation, and user/system-specific features. Our study suggests that continued use intention for an e-learning system is determined by a combination of extrinsic and intrinsic motivation, which function directly or indirectly through user/system-specific factors (i.e., mediators), confirming that both types of motivation exert a joint effect on users' intention of continued usage.

At the extrinsic level, we found visual attractiveness, perceived control, perceived ease of use, perceived usefulness as important extrinsic motives driving users' continued intention to use an elearning system, either directly or indirectly through the mediators. The cognitive-affective framework indicates that environmental factors can cause both cognitive and affective reactions, resulting in behavior, which has successfully been applied in a large quantity of online consumption settings (e.g., References [87, 31]). This might explain why the studied factors of the e-learning 


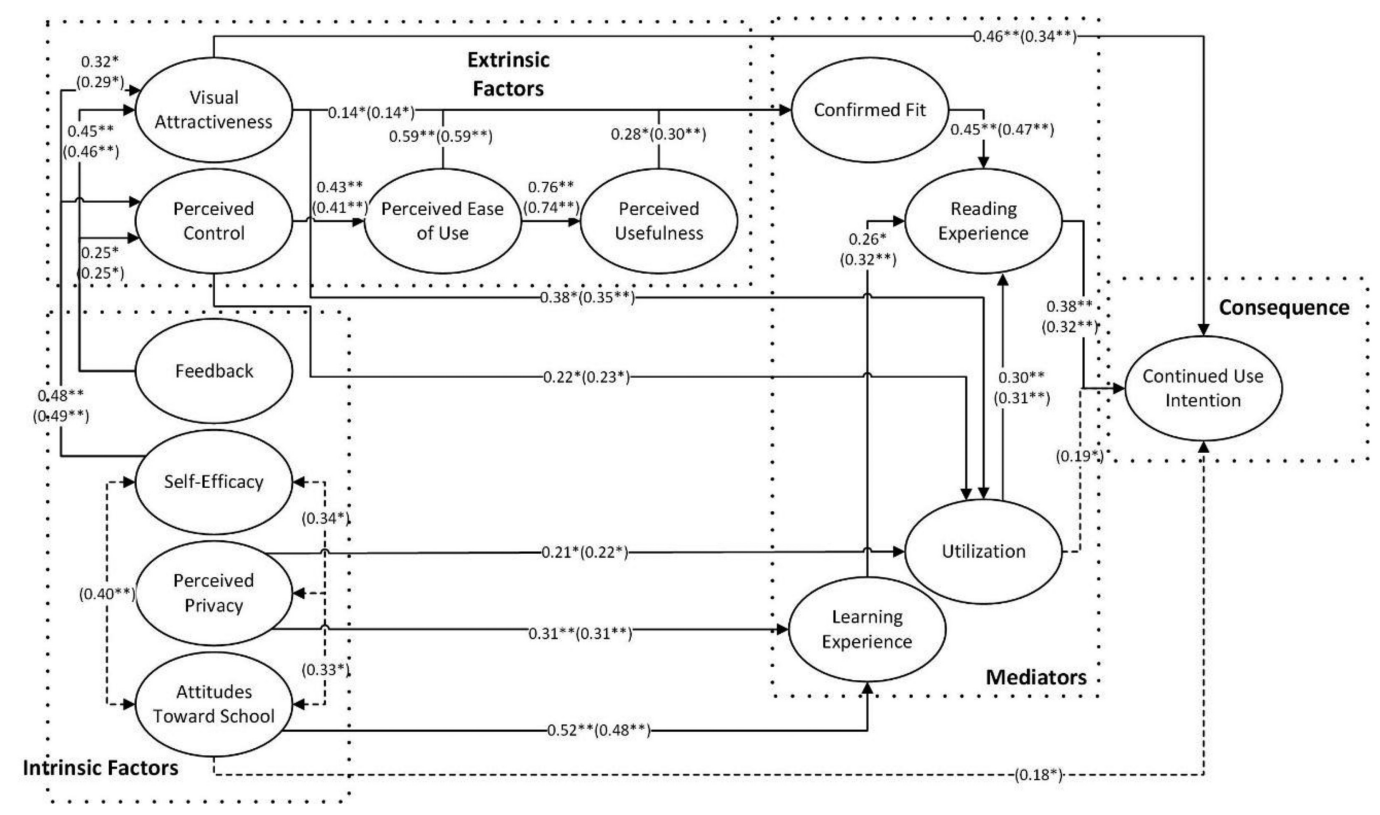

Fig. 7. The result motivation model showing the grouping and sequencing of constructs. (PLS-SEM path coefficients shown out of the brackets and CB-SEM shown in the brackets; ${ }^{*}$ significant at 0.05 level; ${ }^{* *}$ significant at 0.001 level; dashed paths are those only existing in CB-SEM result model).

system environment pertaining to extrinsic-level constructs influence continued use intention not only through utilization (mainly cognition-based) but also through reading experience and confirmed fit (mostly affect-based); confirmed fit combining a user's confirmation of expectation and perceived system-user fit involves both cognitive and affective aspects, corroborating with the cognitive-affective framework. Visual attractiveness is found to be the most important in terms of the total effect on continued use intention and the only extrinsic factor that has a direct effect on continued use intention.

At the intrinsic level, we found self-efficacy, feedback, perceived privacy, and attitudes toward school as important intrinsic motives driving users' continued intention to use an e-learning system, mainly indirectly through the mediators. Dyslexic students' learning motivation is likely to be intrinsically compromised, as they tend to have lower academic self-worth and more coping issues, potentially leading to learned helplessness. From CB-SEM approach, attitudes toward school is found to have a direct effect on continued use intention, while it is not corroborated by PLS-SEM, where it is found to function through full mediation of learning experience and reading experience. Feedback is found to be the most crucial factor among the intrinsic factors in terms of its total effect, meaning the importance of positive and informative feedback that users receive in time during a learning process. Similar with the extrinsic level, the intrinsic-level constructs drive continued use intention through the mediators, i.e., learning and reading experience (mainly affect-based) and utilization (mainly cognition affected), indicating that e-learning systems are expected to have both hedonic and utilitarian benefits. The effects of some intrinsic factors (i.e., self-efficacy and feedback) on continued use intention are also found to be mediated by extrinsic-level constructs (i.e., perceived control and visual attractiveness). 


\subsection{Mediators}

The present data reveal that confirmed fit, learning experience, reading experience, and utilization are the important mediators of the intrinsic/extrinsic motivation-consequence relationship. This has gone beyond the findings of prior research. For example, Zhao et al.'s study has revealed that users' subjective factor about perceived quality of system acts as a mediator between users' concern and acceptance of the system [88], but it was not illustrated what factors are included in the quality of the system. The mediators identified in our study combine the aspects of both users and e-learning systems, reflecting both system-specific features (i.e., confirmed fit, utilization) and user-specific experience (i.e., learning experience, reading experience). This also corresponds with the cognitive-affective framework mentioned before.

Previous work in information system that has considered the impact of user experience and system functions on user motivation for continued usage has yielded equivocal findings (e.g., References $[49,88,89])$. Although reading experience clearly has the potential to impact students' motivation to engage in e-learning systems, especially for dyslexic users, a paucity of work has examined its influence. Among the mediators, our study emphasizes the importance of reading experience (and utilization from CB-SEM), which directly drives the motivational consequence (i.e., continued use intention), and the impact of confirmed fit and learning experience (and utilization from PLS-SEM), as the mediator of extrinsic and intrinsic factors, respectively, also works indirectly on continued use intention through reading experience. The effect of attitudes toward school is found to be mediated by learning and reading experience either fully (in PLS-SEM) or partially (in CB-SEM). Although the direct effect of attitudes toward school is significant in CB-SEM analysis, the strength of the path was, however, relatively weak, which indicates the fact that positive attitudes toward school is not the sufficient condition of continued use intention for e-learning systems, implying the importance of the mediating effect of learning and reading experience.

From a modeling perspective, our motivation model provides a more comprehensive view for explaining or predicting continued use intention of dyslexic students for e-learning systems. The parsimony of prior research of users' IT acceptance has brought about large amounts of debate on the determinants of users' intention of continual usage (see References [52, 90, 91]). To provide greater insights to this end, we have modeled a mixture of extrinsic/intrinsic motivations and system/user characteristics that work as underlying mechanisms behind the motivation to engage in e-learning systems. The connections identified between two types of motivation, as well as their common subsequent dependent variables about system/user characteristics, support Malhotra et al.'s advocacy [92] that we ought to look beyond the distinct taxonomy of extrinsic and intrinsic motivation and treat system usage as a consequence of both intertwined motivations and primary system beliefs. This is especially relevant to e-learning system usage, for which the categorizing line between intrinsic and extrinsic motivation may be vaguer than that for systems with features of only one of utilitarian or hedonic purposes. Two examples that support this claim were provided by Verhagen et al. [31] and Standage et al. [56], who included both extrinsic and intrinsic motivations into their models to explain the motivation to engage in multipurpose information systems and physical education, respectively. Though their models did not directly point out the interconnections of these motivations, and thus seemed to regard them as a dichotomy, they did find that both motivations or their antecedents were correlated. As the combination of extrinsic motivation-such as obtaining good scores or compliments-and intrinsic motivationsuch as acquiring knowledge-is essential to explain e-learning system usage, again our novel perspective that identifies the interrelationships and indivisibility of both motivations can enrich the explanations and understandings behind e-learning system usage. 


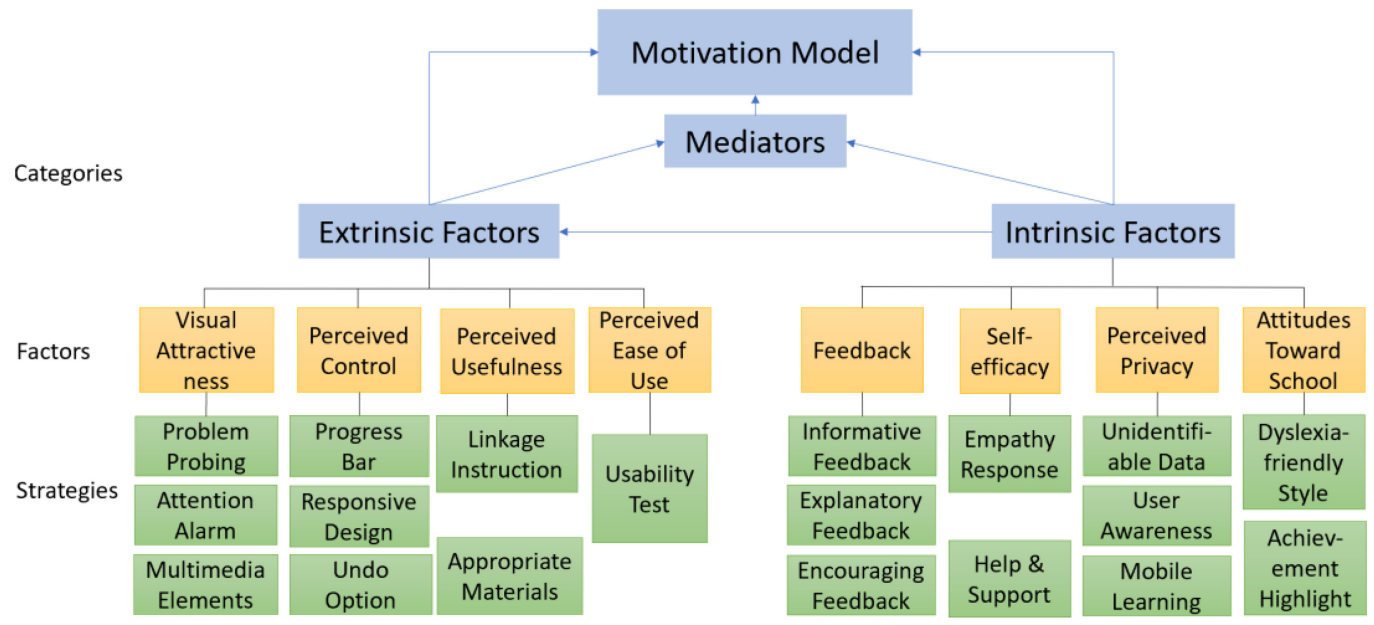

Fig. 8. Motivational strategies or design instructions corresponding to the motivation model.

\subsection{Corresponding Motivational Strategies and Instructions for System Design}

Dyslexia affects the way of learning instead of intelligence and the result of learning, and dyslexic students need personalized education to adapt to their characteristics and preference rather than a one-fits-all solution as a cure. Motivational strategies and well-designed e-learning systems are crucial to enhance the motivation of dyslexic students to learn in e-learning systems. Our motivation model will significantly progress the insight and should be incorporated into such design of motivational strategies and interface in e-learning systems. In the future, the motivation model developed in the present article will be used to assess learners' motivation during their interaction with e-learning systems so personalized strategies or content can be output to user by system to address individual users' motivational needs and enhance their motivation. Any design elements that can potentially increase students' motivation and enhance learning effectiveness can be regarded as motivational strategies. Here, we have listed some typical motivational strategies or instructions designed to address dyslexic students' motivational needs according to our motivation model in the design process. Each intrinsic and extrinsic factor in our model is used to create or relate to corresponding motivational strategies and instructions for system design as examples, shown in Figure 8, which can be applied generally at the start of design process or in specific situations, for example, when the lack of certain motivational factors is self-reported or detected by sensors for a user.

\subsubsection{Corresponding to Extrinsic Factors.}

Visual Attractiveness. As the strongest predictor of motivation among the extrinsic factors found in our study, an e-learning system should look visually appealing to students to attract their attention. Especially for dyslexic students, due to their different ways of learning and more potential difficulties during learning process compared to other students, visual attractiveness is even more important to focus them. Related strategies include problem probing and multimedia elements. Probing a problem at the beginning or in the process of learning can trigger more interest and motivation. Attention alarm can be linked to a rewarding scheme and refocus students by alarming them, for example, about the possible loss of rewards. Dyslexic students may also benefit from attractive multimedia presentations of course elements such as right amount of animation.

Perceived Control. As the new extrinsic factor identified in our study, perceived control relates to users' perceived freedom to choose an action or control the progress during interaction. 
Related strategies include progress bar, responsive design, and undo option. Progress bar is a kind of positive feedback for users in nature, encouraging them all the time about the progress they are making. Responsive design of e-learning systems can respond to the size and orientation of a screen, taking minimal effort from user to adapt to different screens. Undo option refers to the available option to cancel/undo an action and allow users to undo, redo, and repeat an action to avoid out-of-expectation action. The consequence of any action made by a user should be clearly reasonable and interpretable to ensure users' perceived control of the interaction with a system.

Perceived Usefulness. An e-learning system should be useful and effective at facilitating users' learning. Related strategies include linkage instruction and appropriate materials. First, students need to perceive the linkage for how the e-learning courses can help them achieve their learning needs or how the course is related to their daily study or life. Second, since the ways of processing information can vary much among different students, learning materials used in the system should be appropriate and pre-tested to ensure the right amount and difficulty level of information.

Perceived Ease of Use. A well-designed e-learning system should enable students to focus on learning courses with minimal time spent on potential technical issues or confusion about how the system work. As found in our study, perceived control directly influences perceived ease of use, so the strategies pertaining to perceived control mentioned before can also work for perceived ease of use. Most importantly, it is imperative to conduct usability tests and iterative design to ensure the ease of use such as the ease navigation and functionality of e-learning systems.

\subsubsection{Corresponding to Intrinsic Factors.}

Feedback. Output by system to user, suitable feedback can increase users' perceived control of the environment, thus making them more confident in exercising more or moving forward to achieve their learning goals. This is also found as the most important intrinsic factor in terms of its total effect on continued use intention. Related strategies include informative feedback, explanatory feedback, encouraging feedback or a combination of them. Informative feedback makes users aware of what they are doing and the results of their actions, for example, telling users that they are entering quiz part or whether the answer of a quiz is correct. Explanatory feedback allows users' deep understanding on the results of their actions by providing necessary explanations, for example, providing users with the relevant knowledge of a quiz to help them understand why their answers are correct or incorrect. Encouraging feedback can be encouragements in the form of text, voice, or animation output by an e-learning system from an embedded virtual tutor, usually with a reward scheme, it can also improve the visual attractiveness of a system.

Self-efficacy. Students' belief and confidence in completing learning tasks in an e-learning system is formed through their long-term experience, thus hard to be improve significantly for those with a low level of self-efficacy in a short time period, but we can apply strategies to keep them on track and complete the learning task. When their exercise of easily usable e-learning systems increases, they will be more familiar with similar kinds of systems and more confident in using them in the future, which is a positive cycle. Related strategies include empathy response and help and support. Empathy response refers to the empathy provided by the system for user in response to users' possible feelings during their learning process, for example, a virtual tutor appears happy and motivated when a student achieves a learning goal. Help and support should be available to help users keep learning in an e-learning system and avoid the lack of confidence in using the system resulting from the lack of available support.

Perceived Privacy. As the new intrinsic factor identified in our study, privacy issue is easy to be ignored but important especially for dyslexic students, as this might cause more sensitive issues for them such as peer pressure. The pressure from non-dyslexic peers can exacerbate the symptoms of dyslexia [93] and lead to a series of negative feelings of embarrassment, humiliation, anxiety, 
anger, frustration, and guilt [94-96]. Due to the fact of being different from their peers in terms of reading and writing performance, the majority of learners experiencing learning difficulties were being laughed at by their peers and excluded in peer-group tasks and activities assigned in the classroom [97]. Peers of dyslexics may be a reason of their low self-concept and self-esteem [98]; it has also been proved [99] that students with dyslexia are at a disadvantage when interacting with their peers in a synchronous e-learning environment.

There are a lot of strategies to improve users' perceived privacy. Related strategies include unidentifiable data, user awareness, and mobile learning. E-learning systems should store very little personal data or make the user data unidentifiable to protect user privacy. All users should be kept aware of how their data are used and who can access the data. As a subset of e-learning, mobile learning or m-learning emphasizes the portability of the electronic devices such as smartphones used to teach students, and using a smaller screen will help users perceive more private space and safety of their information with much less possibility of being observed. Other ways such as secure access through authentication and encryption can also improve users' perceived privacy and trust.

Attitudes toward School. Improving the attitudes toward school need long-term effort apparently, though providing appealing interface or introducing gamification in e-learning may help in the short term. Dyslexic students' negative attitudes toward school mainly result from the difficulty or boredom experienced in their long-term learning process. Related strategies include dyslexia-friendly style and achievement highlight. Cognitively, e-learning systems should always use dyslexia-friendly style, including fonts and layouts that can be well understood by dyslexic students. For example, some fonts have been specially designed and tested for dyslexic users, such as Open Dyslexic; text should use the shortest words possible and should be replaced or accompanied by comprehensible icons whenever appropriate. Affectively, highlighting their achievements using score or badges during the learning process can help improve confidence. More importantly, using personalized learning approaches and strategies in well-designed e-learning systems as a whole will increase the effectiveness and usage of e-learning system, thus in turn improving the attitudes toward school, forming a positive cycle.

\subsection{Limitations}

It is worth noting that our sample is self-selected from the student members of Dyslexia Norway, inevitably leading to self-selection bias. Though the student members of Dyslexia Norway are also from different schools with different backgrounds, future work is expected to involve more diversity of individuals and school levels. Hierarchical linear modeling techniques allowing the hierarchical and concurrent investigation of individual, group, and cross-level effects within a hierarchical structure will be most applicable in such examinations [56, 100]. Furthermore, according to Standage et al. [56], perceptions of contextual cues, also called motivational climate (i.e., mastery climate and performance climate), have an effect on cognitions, behaviors, and affective responses of physical education students pertaining to achievements [101-103]. Our present study is in the context of "mastery climate" without interpersonal competition. Though it would have been useful to conduct comparable study to investigate the role of contextual cues, our sample size and sample structure did not allow such tests. Another potential limitation of this study is that the e-learning systems investigated and described in the section of Sample and Procedure are all web-based e-learning tools. While the functions of the systems examined are comparable to those of other e-learning tools, we suggest researchers to re-examine and cross-validate the research findings with varying datasets collected in several e-learning systems with contrasting features. Additionally, the intrinsic factors, attitudes toward school, perceived privacy, and self-efficacy are correlated with each other significantly and reflected in the structural 
model from CB-SEM analyses, whereas PLS-SEM does not support incorporation of correlations between constructs into the structural model [80].

\section{CONCLUSION}

An in-depth, comprehensive understanding of motivation to learn is unquestionably crucial in the context of e-learning systems for students with dyslexia. In this study, we have developed a conceptual motivation model based on a priori knowledge and real dyslexic users' views, and further finetune the model through quantitative data analysis techniques including both CB-SEM and PLSSEM to consolidate the findings. We have obtained insights into how educators and e-learning system designers may struggle against the decrease in motivation and engagement levels of students with dyslexia. Specifically, research findings have suggested that overall the impact of learner's intrinsic motivation and extrinsic motivation on continued use intention for e-learning systems is mediated by their learning and reading experience, confirmation of the system-user fit, and utilization of system functions. We have also noticed that in our e-learning context the extrinsic factors and intrinsic ones are not clearly cut, and the factors function in an intertwined manner: The impact of some intrinsic factors on the motivational consequence is mediated by extrinsic factorsboth self-efficacy and feedback output to users have an influence on the visual attractiveness of e-learning systems and users' perceived control. Finally, we have also incorporated our motivation model into the design process by introducing some strategies or instructions as examples to address motivational needs pertaining to each factor in our motivation model. Our future research will be targeted at developing personalization rules based on the motivation model for e-learning systems to output personalized motivational tactics for dyslexic students' enhanced learning.

\section{APPENDIX}

\section{MEASUREMENT SCALES}

$$
* * *=\text { removed after EFA }
$$

\begin{tabular}{ll}
\hline Latent Variables & \multicolumn{1}{c}{ Measured Variables } \\
\hline Perceived Usefulness [32] & $\begin{array}{l}\text { (1) Using the learning tool improves my learning effectiveness. } \\
\text { Mean (SD) = Using the learning tool makes learning easier for me. }\end{array}$ \\
& $\begin{array}{l}\text { (3) Using the learning tool does NOT improve my learning performance. } \\
\text { (reverse) } \\
\text { (4) The learning tool is a useful tool for me. }\end{array}$ \\
Perceived Ease of Use [32] & $\begin{array}{l}\text { (1) Learning how to use the learning tool is easy for me. } \\
\text { (2) My interaction with the learning tool is clear and understandable. }\end{array}$ \\
(3) It is NOT easy for me to become skillful at using the learning tool. (reverse) \\
(4) Overall, I find the learning tool easy to use.
\end{tabular}




\begin{tabular}{|c|c|}
\hline Latent Variables & Measured Variables \\
\hline $\begin{array}{l}\text { Perceived Convenience } \\
{[53]^{* * *}}\end{array}$ & $\begin{array}{l}\text { (1) I can learn at any time via the learning tool. } \\
\text { (2) I can learn at any place via the learning tool. } \\
\text { (3) The learning tool is NOT convenient for me to engage in learning. (reverse) } \\
\text { (4) Overall, I feel that the learning tool is convenient for me to learn knowledge. }\end{array}$ \\
\hline Satisfaction [104] ${ }^{* * *}$ & $\begin{array}{l}\text { (1) Based on my experience with the learning tool, I am very content with using it. } \\
\text { (2) Based on my experience with the learning tool, I am very DISSATISFIED with } \\
\text { using it. } \\
\text { (reverse) } \\
\text { (3) Based on my experience with the learning tool, I am delighted with using it. }\end{array}$ \\
\hline $\begin{array}{l}\text { Confirmation [49] } \\
\text { Mean }(\mathrm{SD})=3.45(1.118)\end{array}$ & $\begin{array}{l}\text { (1) My experience with using the learning tool was better than what I expected. } \\
\text { (2) The service level provided by the learning tool was better than what I expected. } \\
\text { (3) Overall, most expectations for using the learning tool were confirmed. }\end{array}$ \\
\hline $\begin{array}{l}\text { Perceived Fit [104] } \\
\text { Mean (SD) = } 3.46(1.195)\end{array}$ & $\begin{array}{l}\text { (1) Using the learning tool fits with the way I learn. } \\
\text { (2) Using the learning tool does NOT fit with my learning preference. (reverse) } \\
\text { (3) Overall, using the learning tool fits with my learning needs. }\end{array}$ \\
\hline $\begin{array}{l}\text { Feedback [11] } \\
\text { Mean }(S D)=3.06(0.964)\end{array}$ & $\begin{array}{l}\text { (1) The learning tool provides positive feedback. } \\
\text { (2) I did NOT receive compliments in the learning tool. (reverse) } \\
\text { (3) The feedback I received in the learning tool is informative. } \\
\text { (4) The feedback I received in the learning tool is in time. }\end{array}$ \\
\hline
\end{tabular}

Visual Attractiveness (Hair (1) The way things are displayed in the learning tool is attractive.

Jr et al., 2010, Verhagen (2) I do NOT like the way the content looks in the learning tool.

et al., 2012)

Mean $(\mathrm{SD})=3.36(0.909)$

Utilization [49] (1) I utilized the main functions in the tool I used.

Mean (SD) $=3.18$ (0.895) (2) I utilized the most functions in the tool I used.

(3) I completed the learning tasks in the learning tool I used.

(4) I took the self-assessment test/quiz in the learning tool I used.

(1) I could complete the learning tasks using a mobile or web-based learning tool, if there was no one around to tell me what to do.

(2) I could complete the learning tasks using a mobile or web-based learning tool, if I had never used a tool like that before.

Technology Self-efficacy (3) I could complete the learning tasks using a mobile or web-based learning tool, if I [52]

Mean $(\mathrm{SD})=3.70(0.830) \quad$ (4) I could complete the learning tasks using a mobile or web-based learning tool, if I could call someone for help if I got stuck.

(5) I could complete the learning tasks using a mobile or web-based learning tool, if I had a lot of time to complete the learning tasks for which the system was provided.

(6) I could complete the learning tasks using a mobile or web-based learning tool, if someone showed me how to use it first.

Attitudes toward School [54]

(1) I really like school.

Mean $(\mathrm{SD})=3.71(1.078)$

(2) School is BORING. (reverse)

(3) I would NOT like to work in a school when I grow up. (reverse) ***

(4) I am learning a lot in school.

(1) I felt I was able to control the progress as I wanted when using the learning tool.

(2) I felt it was easy to undo or cancel when unpredicted things happen in the learning tool I used.

Perceived Control

Mean $(\mathrm{SD})=3.14(1.013)$

(3) I felt I was able to control the learning progress to adapt to my own learning pace when using the learning tool.

(4) I felt I could manipulate the learning tool I used in the way I like. ***

(5) When I used the learning tool, I felt the progress in the tools was OUT OF MY

CONTROL. (reverse) $)^{* * *}$ 


\begin{tabular}{ll}
\hline Latent Variables & \multicolumn{1}{c}{ Measured Variables } \\
\hline & (1) When using the learning tool, I knew my personal information could be only \\
identified by myself unless I gave permissions. & (2) When using the learning tool, I knew how my personal information would be \\
stored and used.** & (3) When using the learning tool, I felt other people could not have access to my \\
learning progress or any other personal information unless I gave permission. \\
Perceived Privacy \\
Mean (SD) = When using the learning tool, I felt UNSAFE about my personal information \\
overall. (reverse)
\end{tabular}

\section{ACKNOWLEDGMENTS}

The authors would like to thank Dysleksi Norge for their help with recruitment of participants with dyslexia and Norsk Regnesentral for all the support.

\section{REFERENCES}

[1] D. Gooch, A. Vasalou, L. Benton, and R. Khaled. 2016. Using gamification to motivate students with dyslexia using gamification to motivate students with dyslexia. In Proceedings of the CHI Conference on Human Factors in Computing Systems (CHI'16). 969-980.

[2] S. J. Rose. 2009. Identifying and Teaching Children and Young People with Dyslexia and Literacy Difficulties. An independent report to the Secretary of State for Children, Schools and Families. Retrieved from https://dera.ioe.ac.uk/ /14790/.

[3] R. Wang, L. Chen, I. Solheim, T. Schulz, and A. Ayesh. 2017. Conceptual motivation modeling for students with dyslexia for enhanced assistive learning. In Proceedings of the ACM Workshop on Intelligent Interfaces for Ubiquitous and Smart Learning (SmartLearn'17). 11-18.

[4] W. E. Blank and S. Harwell (Eds.). 1997. Promising Practices for Connecting High School to the Real World. University of South Florida, Tampa. Retrieved from https://eric.ed.gov/?id=ED407586.

[5] P. C. Dev. 1997. Intrinsic motivation and academic achievement: What does their relationship imply for the classroom teacher? Remedial Spec. Educ. 18, 1 (1997), 12-19.

[6] S. Walker and D. Prytherch. 2008. How is it for you? (a case for recognising user motivation in the design process). In Affect and Emotion in Human-Computer Interaction: From Theory to Applications, C. Peter and R. Beale (Eds.). Springer Berlin, 130-141.

[7] D. Gefen, 2000. Structural equation modeling and regression: Guidelines for research practice. Commun. AIS 4 (2000).

[8] S. Amaro, C. Seabra, and J. L. Abrantes. 2015. Comparing CB-SEM and PLS-SEM results: An empirical example. In Proceedings of the 2nd International Symposium on Partial Least Squares Path Modeling. 
[9] M. E. Civelek. 2018. Comparison of covariance-based and partial least square structural equation modeling methods under non-normal distribution and small sample size limitations. Euras. Econ. Stat. Empir. Econ. F. 10, 39-50.

[10] I. Ajzen and T. J. Madden. 1986. Prediction of goal-directed behavior: Attitudes, intentions, and perceived behavioral control. F. Exp. Soc. Psychol. 22, 5 (1986), 453-474.

[11] R. M. Ryan and E. L. Deci. 2000. Intrinsic and extrinsic motivations: Classic definitions and new directions. Contemp. Educ. Psychol. 25, 1 (2000), 54-67.

[12] R. H. Shroff and D. R. Vogel. 2009. Assessing the factors deemed to support individual student intrinsic motivation in technology supported online and face-to-face discussions. F. Inf. Technol. Educ. 8 (2009), 59-85.

[13] S. Sun. 2008. An examination of disposition, motivation, and involvement in the new technology context computers in human behavior. Comput. Hum. Behav. 24, 6 (2008), 2723-2740.

[14] E. L. Deci and R. M. Ryan. 2000. The "what" and "why" of goal pursuits: Human needs and the self-determination of behavior. Psychol. Inq. 11, 4 (2002), 227-268.

[15] A. Bandura. 1977. Social Learning Theory. Prentice Hall, Englewood Cliffs, NJ.

[16] A. Bandura. 1997. Self-efficacy: The Exercise of Control. Worth Publishers, New York.

[17] J. M. Keller. 2010. Motivational Design for Learning and Performance: The ARCS Model Approach. Springer, New York, NY.

[18] J. Daki and R. S. Savage. 2010. Solution-focused brief therapy: Impacts on academic and emotional difficulties. f. Educ. Res. 103 (2010), 309-326.

[19] J. Glazzard. 2010. The impact of dyslexia on pupils's self-esteem. Supp. Learn. 25, 2 (2010), 63-70.

[20] R. Burden and J. Burdett. 2005. Factors associated with successful learning in pupils with dyslexia: A motivational analysis. Brit. F. Spec. Educ. 32, 2 (2005), 100-105.

[21] L. Derbali and C. Frasson. 2012. Assessment of learners' motivation during interactions with serious games: A study of some motivational strategies in food-force. Adv. Hum.-comput. Interact. - Special Iss. User Asses. Se. Games Technol.-enhanc. Learn. DOI : https://doi.org/10.1155/2012/624538.

[22] Z. Dor̈nyei. 2001. Motivational Strategies in the Language Classroom. Cambridge University Press.

[23] L. Barolli, A. Koyama, A. Durresi, and G. De Marco. 2006. A web-based e-learning system for increasing study efficiency by stimulating learner's motivation. Inf. Syst. Front. 8 (2006), 297-306.

[24] N. A. Alias. 2012. Design of a motivational scaffold for the Malaysian e-learning environment. Educ. Technol. Soc. 15,1 (2012), 137-151.

[25] I. Arroyo, J. Johns, T. Dragon, and H. Mahadevan. 2007. Repairing disengagement with non-invasive interventions. In Proceedings of the Conference on Artificial Intelligence in Education: Building Technology Rich Learning Contexts That Work. 195-202.

[26] T. Hurley. 2006. Intervention strategies to increase self-efficacy and self-regulation in adaptive on-line learning. Adapt. Hypermed. Adapt. Web-based Syst. 440-444.

[27] C. Chang, C. Chang, and J. Shih. 2016. Motivational strategies in a mobile inquiry-based language learning setting. System 59, (2016), 100-115.

[28] L. Cidrim and F. Madeiro. 2017. Information and communication technology (ICT) applied to dyslexia: Literature review. Rev. CEFAC 19, 1 (2017), 99-108.

[29] K. Dawson, P. Antonenko, H. Lane, and J. Zhu. 2018. Assistive technologies to support students with dyslexia. Teach. Except. Child. 51, 3 (2018), 226-239.

[30] E. Lindeblad. 2017. Assistive technology as reading interventions for children with reading impairments with a one-year follow-up. Disabil. Rehabil. Assist. Technol. 12, 7 (2017), 713-724.

[31] T. Verhagen, F. Feldberg, B. Van Den Hooff, S. Meents, and J. Merikivi. 2012. Understanding users' motivations to engage in virtual worlds: A multipurpose model and empirical testing. Comput. Hum. Behav. 28, 2 (2012), 484-495.

[32] F. D. Davis. 1989. Perceived usefulness, perceived ease of use, and user acceptance of information technology. MIS Quart. 13, 3 (1989), 319-340.

[33] C. C. Chang, C. Liang, C. F. Yan, and J. S. Tseng. 2013. The impact of college students' intrinsic and extrinsic motivation on continuance intention to use English mobile learning systems. Asia-Pacif. Educ. Res. 22, 2 (2013), 181-192.

[34] V. Venkatesh, M. G. Morris, G. B. Davis, and F. D. Davis. 2003. User acceptance of information technology: Toward a unified view. MIS Quart. 27, 3 (2003), 425-478.

[35] M. El-masri and A. Tarhini. 2017. Factors affecting the adoption of e-learning systems in Qatar and USA: Extending the unified theory. Educ. Technol. Res. Dev. 65 (2017), 743-763.

[36] N. Singh, N. Sinha, and F. J. Liébana-Cabanillas. 2020. Determining factors in the adoption and recommendation of mobile wallet services in India: Analysis of the effect of innovativeness, stress to use and social influence. Int. F. Inf. Manag. 50 (2020), 191-205.

[37] B. Park, H. Chang, and S. (Steven) Park. 2019. Adoption of digital devices for children education: Korean case. Telemat. Inform. 38 (2019), 247-256. 
[38] R. M. Tawafak, A. B. T. Romli, R. Bin, and A. Arshah. 2018. Continued intention to use UCOM: Four factors for integrating with a technology acceptance model to moderate the satisfaction of learning. IEEE Access 6, (2018), 66481-66498.

[39] T. C. Herrador-Alcaide, M. Hernández-Solís, and R. S. Galván. 2019. Feelings of satisfaction in mature students of financial accounting in a virtual learning environment: An experience of measurement in higher education. Int. 7 . Educ. Technol. High. Educ. 16, 20 (2019).

[40] A. Hanif, F. Q. Jamal, and M. Imran. 2018. Extending the technology acceptance model for use of e-learning systems by digital learners. IEEE Access 6 (2018), 73395-73404.

[41] F. A. Kimathi and Y. Zhang. 2019. Exploring the general extended technology acceptance model for e-learning approach on student's usage intention on e-learning system in University of Dar es Salaam. Creat. Educ. 10 (2019), 208-223.

[42] C.-T. Chang, J. Hajiyev, and C.-R. Su. 2017. Examining the students' behavioral intention to use e-learning in Azerbaijan? The general extended technology acceptance model for e-learning approach. Comput. Educ. 111 (2017), 128-143.

[43] A. Mehta, N. Morris, B. Swinnerton, and M. Homer. 2019. The influence of values on e-learning adoption. Comput. Educ. 141 (2019), 103617.

[44] T. He and S. L., 2019. A comparative study of digital informal learning: The effects of digital competence and technology expectancy. Brit. f. Educ. Technol. 50, 4 (2019), 1744-1758.

[45] M. Al-Emran, V. Mezhuyev, and A. Kamaludin. 2018. Technology acceptance model in M-learning context: A systematic review. Comput. Educ. 125 (2018), 389-412.

[46] A. Y. Alsobhi, N. Khan, and H. Rahanu. 2015. DAEL framework: A new adaptive e-learning framework for students with dyslexia. Procedia Comput. Sci. 51, (2015), 1947-1956.

[47] Y. Griffiths and M. Stuart. 2013. Reviewing evidence-based practice for pupils with dyslexia and literacy difficulties. f. Res. Read. 36, 1 (2013), 96-116.

[48] R. Wang, L. Chen, and I. Solheim. 2017. A conceptual system architecture for motivation- enhanced learning for students with dyslexia. In Proceedings of the International Conference on E-education, E-business and E-technology. 13-19.

[49] T. J. Larsen, A. M. Sørebø, and Ø. Sørebø, 2009. The role of task-technology fit as users' motivation to continue information system use. Comput. Hum. Behav. 25, 3 (2009), 778-784.

[50] C. Martins, T. Oliveira, and A. Popovič. 2014. Understanding the Internet banking adoption: A unified theory of acceptance and use of technology and perceived risk application. Int. f. Inf. Manag. 34 (2014), 1-13.

[51] J. Moon and Y. Kim. 2001. Extending the TAM for a world-wide-web context. Inf. Manag. 38, 4 (2001), $217-230$.

[52] V. Venkatesh. 2000. Determinants of perceived ease of use: Integrating control, intrinsic motivation, and emotion into the technology acceptance model. Inf. Syst. Res. 11 (2000), 342-365.

[53] Y. Lee, J. Lee, and Y. Hwang. 2015. Relating motivation to information and communication technology acceptance: Self-determination theory perspective. Comput. Hum. Behav. 51 (2015), 418-428.

[54] L. A. Mills, G. A. Knezek, and J. S. Wakefield. 2013. Understanding information seeking behavior in technology pervasive learning environments of the 21st century. Turk. Onl. f. Educ. Technol. 12, 4 (2013), 200-208.

[55] G. S. Leng, S. Lada, and M. Z. Muhammad. 2011. An exploration of social networking sites (SNS) adoption in malaysia using technology acceptance model (TAM), theory of planned behavior (TPB) and intrinsic motivation. f. Internet Bank. Commer. 16, 2 (2011).

[56] M. Standage, J. L. Duda, and N. Ntoumanis. 2003. A model of contextual motivation in physical education: Using constructs from self-determination and achievement goal theories to predict physical activity intentions. 7 . Educ. Psychol 95, 1 (2003), 97-110.

[57] J. B. Ullman. 2001. Structural equation modeling. In Using Multivariate Statistics (4th ed.), B. G. Tabachnick and L. S. Fidell (Eds.). Allyn \& Bacon, Needham Heights, MA, 653-771.

[58] J. B. Schreiber, F. K. Stage, J. King, A. Nora, and E. A. Barlow. 2006. Reporting structural equation modeling and confirmatory factor analysis results: A review. Journal of Educational Research 99, 6 (2006), 323-338.

[59] J. F. Hair Jr., L. M. Matthews, R. L. Matthews, and M. Sarstedt. 2017. PLS-SEM or CB-SEM: updated guidelines on which method to use. Int. f. Multivar. Data Anal. 1, 2 (2017), 107-123.

[60] W. J. Reinartz, M. Haenlein, and J. Henseler. 2009. An empirical comparison of the efficacy of covariance-based and variance-based SEM. Int. F. Mark. Res. 26, 4 (2009), 332-344.

[61] J. L. Arbuckle. 2013. Amos (Version 22.0). IBM SPSS, Chicago.

[62] C. M. Ringle, S. Wende, and J.-M. Becker. 2015. SmartPLS 3. SmartPLS, Bönningstedt.

[63] D. L. Goodhue, W. Lewis, and R. Thompson. 2012. Does PLS have advantages for small sample size or non-normal data?. MIS Quart. 36, 3 (2012), 981-1001.

[64] H. W. Marsh, J. R. Balla, and R. P. McDonald. 1988. Goodness-of-fit indexes in confirmatory factor analysis: The effect of sample size. Psychol. Bull. 103, 3 (1988), 391-410. 
[65] J. F. Hair, C. M. Ringle, and M. Sarstedt. 2012. Partial least squares: The better approach to structural equation modeling? Long Range Plann. 45, 5-6, (2012), 312-319.

[66] J. F. Hair Jr, W. C. Black, B. J. Babin, and R. E. Anderson, 2010. Multivariate Data Analysis. Pearson Education.

[67] C. Fornell and D. F. Larcker. 1981. Evaluating structural equation models with unobservable variables and measurement error. F. Mark. Res. 18, 1 (1981), 39-50.

[68] N. Kock. 2015. Common method bias in PLS-SEM: A full collinearity assessment approach. Int. f. e-Collab. 11, 4 (2015), 1-10.

[69] R. K. Chellappa and P. A. Pavlou. 2002. Perceived information security, financial liability and consumer trust in electronic commerce transactions. Logist. Inf. Manag. 15, 5/6, (2002), 358-368.

[70] M. A. Patton and A. Jøsang. 2004. Technologies for trust in electronic commerce. Electron. Commer. Res 4, 1-2, (2004), $9-21$.

[71] H.-L. Chou and C.-H. Chen. 2016. Beyond identifying privacy issues in e-learning settings-Implications for instructional designers. Comput. Educ 103, C, (2016), 124-133.

[72] V. Terzis, C. N. Moridis, and A. A. Economides. 2012. How student's personality traits affect computer based assessment acceptance: Integrating BFI with CBAAM. Comput. Hum. Behav 28, 5 (2012), 1985-1996.

[73] B. Wheaton, B. Muthén, D. F. Alwin, and G. F. Summers. 1977. Assessing reliability and stability in panel models. Sociol. Methodol. 8 (1977), 84-136.

[74] B. M. Byrne. 2006. Structural Equation Modeling with EQS: Basic Concepts, Applications, and Programming. Lawrence Erlbaum, Mahwah, NJ.

[75] I. Hu and P. M. Bentler. 1999. Cutoff criteria for fit indexes in covariance structure analysis: Conventional criteria versus new alternatives. Struct. Equ. Model. A Multidiscip. J. 6, 1 (1999), 1-55.

[76] J. Henseler, C. M. Ringle, and R. R. Sinkovics. 2009. The use of partial least squares path modeling in international marketing. New Challenges to International Marketing (Advances in International Marketing), Vol. 20. 277-319.

[77] J. F. Hair Jr., C. M. Ringle, and M. Sarstedt. 2013. Partial least squares structural equation modeling: Rigorous applications, better results and higher acceptance. Long Range Plann. 46, 1-2 (2013) 1-12.

[78] M. Stone. 1974. Cross-validatory choice and assessment of statistical predictions. F. R. Stat. Soc. 36, 2 (1974), 111-147.

[79] S. Geisser. 1974. A predictive approach to the random effects model. Biometrika 61, 1 (1974), 101-107.

[80] K. K. Wong. 2013. Partial least squares structural equation modeling (PLS-SEM) techniques using smartPLS. Mark. Bull. 24 (2013).

[81] W. W. Chin. 1998. The partial least squares approach for structural equation modeling. In Modern Methods for Business Research, G. A. Macoulides (Ed.). Lawrence Erlbaum Associates, Mahwah, NJ, 295-336.

[82] J. Cohen. 1988. Statistical Power Analysis for the Behavioral Sciences (2nd ed.). Lawrence Erlbaum Associates, Mahwah, NJ.

[83] X. Zhao, J. G. Lynch Jr., and Q. Chen. 2010. Reconsidering Baron and Kenny: Myths and truths about mediation analysis. f. Consum. Res. 37, 2 (2010), 197-206.

[84] S. A. Nikou and A. A. Economides. 2017. Mobile-based assessment: Integrating acceptance and motivational factors into a combined model of self-determination theory and technology acceptance. Comput. Educ. 109, C (2017), 56-73.

[85] M. Fetscherin and C. Lattemann. 2008. User acceptance of virtual worlds. F. Electron. Commer. Res. 9, 3 (2008), 231242.

[86] J. Merikivi. 2009. What Habbo goers do in practice? Decomposing attitudinal beliefs. In Proceedings of the 17th European Conference on Information Systems.

[87] S. A. Eroglu, K. A. Machleit, and L. M. Davis. 2001. Atmospheric qualities of online retailing: A conceptual model and implications. J. Bus. Res. 54, 2 (2001), 177-184.

[88] Y. Zhao, J. Ye, and T. Henderson. 2016. The effect of privacy concerns on privacy recommenders. In Proceedings of the 21st International Conference on Intelligent User Interfaces. 218-227.

[89] S. Liaw. 2008. Investigating students' perceived satisfaction, behavioral intention, and effectiveness of e-learning: A case study of the Blackboard system. 51 (2008), 864-873.

[90] C. R. Plouffe, J. Hulland, and M. Vandenbosch. 2001. Research report: Richness versus parsimony in modeling technology adoption decisions-understanding merchant adoption of a smart card-based payment system. Inf. Syst. Res. 12,2 (2001), 208-222.

[91] J. C. Roca and M. Gagne. 2008. Understanding e-learning continuance intention in the workplace: A selfdetermination theory perspective. Comput. Hum. Behav. 24 (2008), 1585-1604

[92] Y. Malhotra, D. Galletta, and L. Kirsch. 2008. How endogenous motivations influence user intentions: Beyond the dichotomy of extrinsic and intrinsic user motivations. f. Manag. Inf. Syst. 25, 1 (2008), 267-300.

[93] S. Stienen-Durand and J. George. 2014. Supporting dyslexia in the programming classroom. In DSAI 2013, Procedia - Procedia Computer Science 27 (2014), 419-430. 
[94] R. A. Taj and M. A. Malik. 2010. Conclusive study to uncover the attributors for success and failure of learning disabled children. Eur. F. Soc. Sci. 16, 4 (2010), 590-592.

[95] R. M. Klassen and S. L. Lynch. 2007. Self-efficacy from the perspective of adolescents with LD and their specialist teachers. F. Learn. Disabil. 40, 7 (2007), 494-507.

[96] N. Alexander-Passe. 2008. The sources and manifestations of stress amongst school-aged dyslexics, compared with sibling controls. Dyslexia 14, 4 (2008), 291-313.

[97] P. Mweli. 2012. Exploring learners' experiences of inclusive education: The voice of the voiceless. Retrieved from https://eric.ed.gov/?id=ED544051.

[98] N. Humphrey. 2002. Self-concept and self-esteem in developmental dyslexia. Brit. F. Spec. Educ. 29, 1 (2002), 29-36.

[99] B. P. Woodfine, M. Baptista Nunes, and D. J. Wright. 2008. Text-based synchronous e-learning and dyslexia: Not necessarily the perfect match! Comput. Educ. 50 (2008), 703-717.

[100] H. Goldstein. 2003. Multilevel Statistical Models (3rd ed). Hodder Arnold, London.

[101] M. Goudas and S. J. H. Biddle. 1994. Perceived motivational climate and intrinsic motivation in school physical education classes. Eur. F. Psychol. Educ. 9, 3 (1994), 241-250.

[102] P. Athanasios. 1994. Development of a questionnaire to measure achievement orientations in physical education. Res. Q. Exerc. Sport 65, 1 (1994), 11-20.

[103] D. C. Treasure and G. C. Roberts. 2001. Students' perceptions of the motivational climate, achievement beliefs and satisfaction in physical education. Res. Q. Exerc. Sport 72, 2 (2001), 165-175.

[104] R. L. Oliver. 1980. A cognitive model of the antecedents and consequences of satisfaction decisions. F. Mark. Res. 17, 4 (1980), 460 .

Received February 2019; revised July 2019; accepted September 2019 